\title{
Off-grid appliance performance testing: results and trends for early-stage market development
}

\author{
Elisa Lai · Stewart Muir • Yasemin Erboy Ruff
}

Received: 2 July 2018 / Accepted: 15 April 2019 / Published online: 22 May 2019

(C) The Author(s) 2019

\begin{abstract}
High-quality, efficient, and off-grid appropriate appliances play an essential role in developing the distributed clean energy market - but little data or market intelligence exists to help market actors make informed decisions. To fill this significant knowledge gap, CLASP, in support of the Efficiency for Access Coalition, has developed the Off-Grid Appliance Data Platform: an off-grid appliance performance database. Based on analysis of the test data from the Platform, the paper provides a glimpse into the current status, efficiency and cost trends, and remaining challenges gleaned from the off-grid television, fan, and refrigeration market - top three appliances with significant potential to scale. The analyses show a wide variation in the efficiency of products across the market. Efficiency improvements are observed, albeit slowly. Analysis shows that prices are decreasing, but have not yet reached a level of affordability for off-grid consumers in Africa and South Asia. Through the appliance performance testing results and market trends, the authors of this paper hope to enhance the global knowledge about off-grid appliances performance. Further research and
\end{abstract}

E. Lai $(\bowtie) \cdot$ Y. Erboy Ruff

CLASP, 1401 K St. NW, Washington, DC 20005, USA

e-mail: elai@clasp.ngo

Y. Erboy Ruff

e-mail: yerboyruff@ clasp.ngo

\section{S. Muir}

Energy Saving Trust, 30 North Colonnade, London E14 5GP, UK e-mail: stewart.muir@est.org.uk data collection around sales trends will enhance the comprehensiveness and robustness of future analyses of off-grid appliances.

Keywords Appliances · Energy efficiency · Test methods $\cdot$ Market trends $\cdot$ Laboratory testing $\cdot$ Field testing

\section{Introduction}

With dependable connectivity remaining often unrealistic and/or cost-prohibitive in many "off-grid" regions, distributed renewable energy systems, such as minigrids and solar home systems (SHSs), have the potential to instead serve as the primary means to provide a first access point for life-changing modern energy services. High-quality, efficient, and off-grid appropriate appliances such as fans, TVs, and refrigerators play an essential role in offering off-grid communities further benefits from their energy systems (Hirmer and Guthrie, 2017), as well as developing and sustaining the distributed clean energy market in a positive cycle.

However, the current off-grid appliance market is nascent and disorganized. To enable appliances to be powered by SHSs, they must be highly efficient, with many conventional appliances consuming too much energy for this to be possible (Phadke et al., 2015). There is demand from a variety of market players for access to product and impact data and other valuable market intelligence (GOGLA and Lighting Global, 2016). But little information exists throughout the 
supply chain (Efficiency for Access Coalition, 2018), inhibiting manufacturers, energy service companies, distributors, investors, policymakers, and consumers themselves from taking smart action, slowing market development and the effective delivery of modern energy services to the communities that need them most.

For example, product manufacturers often have insufficient market intelligence to develop off-grid appropriate products that meet consumer needs and technical demands presented by small-scale distributed solar energy systems. Interviews with distributed energy service companies (DESCOs) suggest they have insufficient market intelligence and thus need to invest significant resources to identify and source appropriate appliances that work with their distributed energy system offerings. In addition, policymakers in developing markets lack data with which to identify solutions to various energy challenges (Leo et al., 2018). Access to comprehensive product performance data and testing capacity has helped to establish a robust baseline for associated policy instruments to be set in several on-grid markets, which could be replicated in the off-grid sector. Along the same vein, investors, micro-finance institutions, and financial lenders often perceive off-grid sector investments as too risky, since they lack reliable benchmarks and market intelligence to perform better due diligence on companies and assess potential risks for project investments accurately (United Nations Development Programme, 2018).

Existing databases and informational resources for the off-grid solar sector are typically product listings ${ }^{1}$ that help product distributors to identify and source distributed energy system components and off-grid appliances. While these tools are quite useful, the addition of performance data would greatly enhance their utility. This lack of reliable data with which to benchmark appliance performance puts efficient, high-quality products at a competitive disadvantage. At the end of the supply chain, consumers are price-sensitive and do not have enough information about the durability and energy efficiency of off-grid appliances-which often prompt consumers to make purchase decisions based on price alone. Efforts such as making appliance performance databases available to end-users, encouraging industry-standardized performance reporting metrics and consumer awareness campaigns, are the first steps

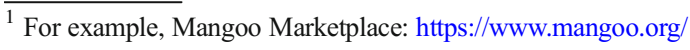

to bridge the gap in helping consumers make more informed purchase decisions.

Bridging the off-grid appliance data gap

Product databases are a commonly used tool in the ongrid market to help policymakers monitor products sold in a given domestic market, e.g., the Australian Energy Rating Product Registration Database, ${ }^{2}$ or the international Topten ${ }^{3}$ initiative, which presents the most efficient technology and market analysis on energy performance. Other databases provide product ratings and reviews to help consumers compare products, e.g., Consumer Reports. ${ }^{4}$ However, for off-grid appliances, there is no existing technical infrastructure or equivalent practice of conducting product testing and data sharing in a consistent way. While there are existing product databases for the off-grid solar sector to help address product sourcing challenges and streamline business-to-business transactions, ${ }^{5}$ the performance data referenced in these databases are primarily based on manufacturers' claims, using different performance metric and thus making it difficult to compare products.

The Off-Grid Appliance Data Platform ${ }^{6}$ developed by the Efficiency for Access Coalition ${ }^{7}$ is a first attempt to address this challenge by generating and sharing accurate and consistent product performance data for the off-grid market. The program samples off-grid appliances from retail markets, distributors, and manufacturers; tests them according to Global LEAP off-grid appliance test methods ${ }^{8}$; and shares the independently tested performance data. The Platform provides

\footnotetext{
$\overline{2}$ Australian Government Department of the Environment and Energy: http://reg.energyrating.gov.au/comparator/

${ }^{3}$ Topten Initiative is mainly covering Europe but also active in China and South America. Topten Europe: www.topten.eu

${ }^{4}$ Consumer Reports: https://www.consumerreports.org/cro/index.htm

${ }^{5}$ For example, Mangoo Marketplace (https://www.mangoo.org/) and Odyssey Energy Solutions (https://www.odysseyenergysolutions. com/) list solar products and technical specifications based on manufacturers' claims.

${ }^{6}$ Efficiency for Access. Off-Grid Appliance Data Platform: $\mathrm{https}$ ://efficiencyforaccess.org/data-platform.

${ }^{7}$ The Platform is currently supported by the Good Energies Foundation and the UK Department for International Development (DfID)'s Low-Energy Inclusive Appliances (LEIA) Programme under the newly scaled up Efficiency for Access Coalition, which brings together donors, development organizations, and philanthropic organizations to accelerate global energy access through energy-efficient appliances, and for which CLASP and EST serve as the Secretariat. https://efficiencyforaccess.org/

${ }^{8}$ Global LEAP Awards: https://globalleapawards.org/
} 
information about performance, durability, quality, and cost to enable comparison and evaluation across off-grid products. The Platform currently includes test data for off-grid-appropriate TVs, fans, and refrigerators. With the absence of consumer protection mechanisms for offgrid appliances, the test methods and test data generated by the Data Platform could serve as a technical foundation for future development of a quality assurance program and policy frameworks, such as standards and labeling programs.

With this framework in mind, this paper provides a glimpse into the current status, observed efficiency and cost trends, and remaining challenges gleaned from the off-grid TV, fan, and refrigeration markets. The analyses presented in the paper are primarily based on market surveys and test data collected through the Data Platform, ${ }^{9}$ supplemented with third-party sources for ongrid products. Test data enables the assessment of trends in the energy efficiency of products, while market survey data provides a detailed picture of the range of product specifications available in the market.

\section{Methodology}

Analysis

The primary purpose of the analyses is to show and identify market trends on efficiency and pricing of offgrid appliances. TVs, fans, and refrigerators were selected as the focus of this paper because these products are identified as the off-grid appliance most-in-demand by un- and under-electrified consumers (Efficiency for Access Coalition, 2018). The off-grid appliance data used in the paper was gathered from the Efficiency for Access Data Platform. In the following analysis, the products are often grouped into two categories: (1) market leading products that were identified as Winners and Finalists of Global LEAP Awards competitions. ${ }^{10}$ In this analysis, these are defined as "Awards" products; and (2) baseline products that are typical of the general market. In this analysis, these are defined as "Baseline" products. By analyzing the performance of these two groups of products, the paper establishes a baseline of

\footnotetext{
${ }^{9}$ Efficiency for Access Off-Grid Appliance Data Platform: https://efficiencyforaccess.org/data-platform. (Database is currently being beta-tested.)

${ }^{10}$ Global LEAP Awards: https://globalleapawards.org/
}

efficiency for off-grid TVs, fans, and refrigerators and plots the performance gap between best available technology and the least efficient products on the market.

Further to this, figures based on Data Platform data were supplemented by market data collected in 2018 from multiple countries, including Kenya, Tanzania, Pakistan, and India. Off-grid appliances were identified through a series of market surveys, which collect basic product information such as brand and model names, product sizing, rated power consumption, and retail price. This provided insights into the variety of product sizes available, the split of AC and DC models, variations in different national markets, and the range of prices. Test data enabled the relationship between products' efficiency and price to be established to assess the relative affordability of the most efficient models. Yearon-year trends for efficiency and cost were also explored and trends mapped.

Beyond the market snapshot enabled by the above comparisons, the analysis also addressed two further market intelligence aspects. From test data, a comparison was made of reported values (from product literature or packaging) against tested figures, to assess the accuracy of information presented by suppliers. Reported figures may be the only source of performance data for stakeholders in the absence of extensive test data. And finally, performance and cost comparisons were made between Data Platform products and on-grid products, to track the current progress of off-grid technologies.

Off-grid appliance test methods

Independent laboratory testing helps product manufacturers to ensure that their products perform as expected in terms of their energy efficiency and quality. Standardized test methods can be used to evaluate product characteristics, quality, and energy performance, thus enabling consistent product-to-product comparisons. However, most of international test methods and standards for energy performance and quality of products mainly address specific use cases for products in on-grid sector - and may not be sufficient for evaluating offgrid product characteristics and performance.

Off-grid appliances, in many ways, use similar technologies, components, and design considerations to products used in developed on-grid markets. However, off-grid appliances are often used in rural areas in Sub-Saharan Africa and South Asia, where the ambient weather conditions tend to be warm and humid. Because these 
Table 1 Off-grid appliance testing parameters and modifications

\begin{tabular}{|c|c|c|}
\hline Product & Commonly used test methods for on-grid household products & $\begin{array}{l}\text { Modified tests to address } \\
\text { off-grid performance characteristics }\end{array}$ \\
\hline Fans & $\begin{array}{l}\text {-IEC } 60879 \text { (air delivery, power input, and } \\
\text { energy efficiency value) } \\
\text {-IEC 60335-2-80 (fan blades and guards) }\end{array}$ & $\begin{array}{l}\text {-Quality and workmanship inspections } \\
\text {-Voltage fluctuation conditions ( } \pm 15 \% \text { of rated voltage) } \\
\text { - Harsh environment exposure conditions }\left(40 \pm 2{ }^{\circ} \mathrm{C}\right. \\
\text { temperature and } 93 \pm 3 \% \text { relative humidity) } \\
\text {-Physical Ingress Protection (IEC } 62257-9-5) \\
\text {-Drop test (IEC TS } 62257-9-5)\end{array}$ \\
\hline TVs & $\begin{array}{l}\text {-IEC } 62087 \text { (On Mode power consumption) } \\
\text { •IEC } 62301 \text { (Standby Mode power consumption) } \\
\text { •ENERGY STAR® Televisions Test Method (luminance) }\end{array}$ & $\begin{array}{l}\text {-Quality and workmanship inspections } \\
\text {-Voltage fluctuation conditions ( } \pm 15 \% \text { of rated voltage) } \\
\text { - Harsh environment exposure conditions }\left(40 \pm 2{ }^{\circ} \mathrm{C}\right. \\
\text { temperature and } 93 \pm 3 \% \text { relative humidity) } \\
\text {-Physical Ingress Protection (IEC } 62257-9-5) \\
\text {-Viewing Angle (IEC } 60107 \text { ) }\end{array}$ \\
\hline Refrigerators & $\begin{array}{l}\text {-IEC } 62552 \text { (steady-state operation power } \\
\text { consumption, freezing capacity) } \\
\text { - WHO/PQS/E003/RF05-VP.4 (autonomy time, pull-down time) }\end{array}$ & $\begin{array}{l}\text {-Quality and workmanship inspection } \\
\text {-Voltage fluctuation conditions ( } \pm 15 \% \text { of rated voltage) } \\
\text { - Harsh environment exposure conditions }\left(43 \pm 2{ }^{\circ} \mathrm{C}\right. \\
\quad \text { temperature and } 93 \pm 3 \% \text { relative humidity) }\end{array}$ \\
\hline
\end{tabular}

appliances are often used with a solar PV and battery module, products are also exposed to voltage fluctuations, causing a higher failure rate (Urmee et al., 2016).

The quality and durability of off-grid products are therefore key considerations for off-grid consumers living in these regions, many of whom live in extreme poverty and have to invest a relatively large portion of their disposable income on solar systems or accompanying appliances (Hammond et al., 2007). They also live in remote areas with almost no access to repair technicians or replacement components. Once an appliance stops working, most off-grid households cannot afford to repair or replace faulty appliances.

To enable improved comparisons of off- and weakgrid appropriate appliances, Global LEAP ${ }^{11}$ program developed a set of test methods to evaluate energy performance, quality, and durability of appliances used in off-grid and weak-grid settings (Table 1). These offgrid appliance test methods leverage existing international test methods - such as those by the International Electrotechnical Commission (IEC) ${ }^{12}$ - that are commonly used to measure energy performance of on-grid product counterparts. These test methods, in some cases, are slightly modified to better enable the evaluation of specific "off-grid characteristics." For example, voltage fluctuation testing for off-grid TVs was based on energy

\footnotetext{
${ }^{11}$ Global LEAP: http://globalleap.org/

${ }^{12}$ International Electrotechnical Commission: http://www.iec.ch/
}

consumption testing in IEC 62087 and modified with high and low input voltages during the test. Because the quality of off-grid appliance varies significantly, the test methods were modified to include a visual inspection conducted by the test technicians at the laboratories to evaluate product's enclosure, screen, wiring, fittings, and connections for any visible defects. ${ }^{13}$

The test methods were developed through a rigorous research, consultation, and review process that included a working group of off-grid energy industry stakeholders, appliance manufacturers, policymakers, and test facilities. The test data used in the following analyses are measured based on the off-grid TV, fan, and refrigerator test methods listed above.

\section{Results and analysis}

\section{Overview}

This section showcases the current status, efficiencyrelated trends, and remaining challenges gleaned from the off-grid TV, fan, and refrigeration markets, including product-by-product efficiency and quality comparisons between off-grid and on-grid appropriate counterparts where possible.

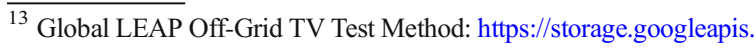
com/e4a-website-assets/Global-LEAP-Off-Grid-TV-Test-Method.pdf
} 
Off-grid and weak-grid televisions

\section{Current state of the off-grid TV market}

Consumer demand for TVs is a primary driver of demand for off-grid energy generation; thus, scaling the off-grid TV market has significant implications for offgrid power system penetration overall. A recent Global LEAP survey found that TVs are often the next appliance that off-grid consumers desire to own after obtaining basic lighting energy services (Global LEAP, 2017). The Off-Grid Solar Market Trends Report ( 2018) cited a survey in rural India in 2017 showing that women who had cable TV access displayed a stronger preference to send girls to school and a lower son preference, exhibited more autonomy, and showed less tolerance for spousal abuse.

Improved TV efficiency also has the potential to reduce the price of SHSs to the end-customer. Park and Phadke (2017) estimated that highly efficient, DCpowered LED-LCD TVs could decrease the overall cost of SHSs by around $25 \%$ by enabling use of PV and battery systems up to $50 \%$ smaller than those required to power an LED-LCD TV of "standard" efficiency. While applying certain design features to increase the efficiency of TVs was found to add to the manufacturing cost in the study, this increase was seen to be less than the savings that could be achieved by decreasing the size of the SHS.

Even though the market for grid-powered TVs is highly developed, to the point of saturation and decline, the market for off- and weak-grid-appropriate TVs remains nascent and inhibited by various market barriers, such as affordability of efficient televisions and limited product availability in rural markets. Recent estimates suggest that the annual global market for off-gridcompatible TVs could grow more than triple-from $\$ 1.024$ to $\$ 3.126$ billion-with efficiency and design improvements while reducing costs (Global LEAP, 2016).

\section{Off-grid television data trends}

Product characteristics LED-LCD TVs remain the most commonly available TV technology in the market today. Park and Phadke (2017) reported that $95 \%$ of all new TVs shipped in 2014 were LCD models.

Manufacturer specifications for 286 off-gridappropriate TVs were available from market surveys in Kenya, Tanzania, Uganda, and Sierra Leone. Of these TVs, 261 were recorded as being suitable for either onor off-grid application, with 25 defined as solely offgrid. Earlier off-grid TVs were observed to be at the smaller end of the size spectrum (four of the seven 2013/ 14 Global LEAP Award Winner or Finalist models were 15.5 in. models), but the size distribution from the Market Survey shows that larger screen sizes were seen at a similar frequency to small screen sizes (as defined in Table 2).

The "medium" (18-24 in.) size bracket was observed to contain the highest percentage of models overall. The segment for TVs over 25 in. was seen to be a similar size to that for "small" TVs, suggesting that market penetration of larger sizes is increasing - in particular, this appeared to be the case in the Kenyan market. As market surveys were carried out in large cities such as Kampala and Nairobi, it is expected that some of these products are aimed at people living in more urban areas, with likely higher incomes and greater grid connectivity, rather than solely at rural, off-grid users with potentially less purchasing power.

It is expected that cost is the main driver of the screen sizes acquired by off-grid TV customers, with only smaller screen size models able to be afforded by many. There is some anecdotal evidence that rural customers would prefer a larger TV for cases where a larger family or members of a community may watch TV together (Global LEAP, 2016).

Some screen sizes are more widespread than others, where a specific size of screen and shell is produced at scale. The distribution of screen sizes in Fig. 1 shows the 24 and 32 in. models are common, which correlates with the most common sizes in on-grid markets; production of these sizes for the African and South Asian markets should therefore benefit from economies of scale. A fairly high share was also seen for the 17 and 19 in. sizes, even though demand for these sizes is not high in

Table 2 Split of off-grid-appropriate TVs by size and country from 2018 market survey

\begin{tabular}{|c|c|c|c|c|c|}
\hline Size & Kenya & Uganda & Tanzania & $\begin{array}{l}\text { Sierra } \\
\text { Leone }\end{array}$ & Total \\
\hline Small (12-17 in.) & 9 & 22 & 31 & 1 & 63 \\
\hline $\begin{array}{l}\text { Medium } \\
\quad(18-24 \text { in.) }\end{array}$ & 32 & 68 & 55 & 3 & 158 \\
\hline Large (25+) & 31 & 9 & 19 & 6 & 65 \\
\hline
\end{tabular}




\section{Distribution of Screen Sizes seen in 2018 LEIA market survey}

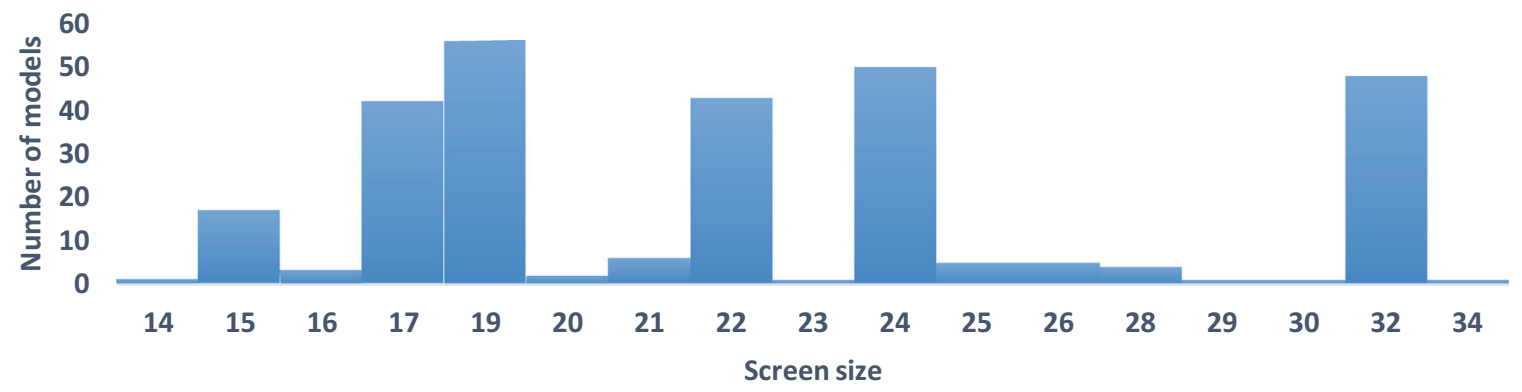

Fig. 1 Distribution of TV screen sizes from 2018 market survey

on-grid markets such as Europe and the USA (Euromonitor International, 2018).

The split of direct current (DC) vs. alternating current (AC) TVs was also assessed. Some AC TVs were reported as being available with inverters that can function with off-grid systems, or with adaptors for use in either capacity. Seventeen percent of TVs recorded were categorized as DC only, with the majority (79\%) categorized as AC/DC, suggesting that DC-only TVs are yet to achieve significant market penetration.

Efficiency trends For the purposes of this study, TV energy efficiency is defined by the energy efficiency index (EEI), which is a measure of the input power in Watts per unit area of screen size in square inches (i.e., the lower the EEI, the more efficient the TV). Test data was analyzed to track efficiency improvements from the first models tested in 2013 up to the current period (most recent data being from 2017) with trends displayed in Tables 3 and 4.

Global LEAP Award winners and finalists are chosen based on quality and durability assessments as well as energy efficiency gains. While the number of data points is relatively small, the efficiency of Winners and
Finalists did see an overall increase between 2013/ 2014 and 2016/2017.

More data points are available from testing conducted in 2016 and 2017 than 2014 and 2015. The most efficient product tested in 2017 (a 32-in. TV with onmode power measured at $13.64 \mathrm{~W}$ ), used $35 \%$ less power at the same screen size than the most efficient TV seen in 2016 (a 32-in. TV with on-mode power measured at $20.85 \mathrm{~W}$ ). Another interesting comparison was the difference between the most and least efficient models tested. Years 2014 and 2015 only saw the testing of Awards products, most of which would be expected to be towards the higher end of the efficiency spectrum. However, in 2016 and 2017 when a broader segment of the market was tested, the least efficient TV was seen to have an EEI five times that of the most efficient; this increased to nearly a factor of eight in 2017. The distribution of the various efficiency indexes for TVs is shown below, comparing the baseline models to the Award winners. Non-award winning products from 2016/2017 (defined as "baseline") remained significantly less efficient than winning products from 2013/2014 (Fig. 2).

Table 3 Energy efficiency trend for Global LEAP Award winners and finalists by year

\begin{tabular}{llll}
\hline Tested models & \multicolumn{2}{l}{ Energy efficiency index $\left(\mathrm{W} /\right.$ in. $\left.{ }^{2}\right)$ by year } \\
\cline { 2 - 4 } & $2013 / 2014(n=7)$ & $2015 / 2016(n=13)$ & $2016 / 2017(n=15)$ \\
\hline Mean EEI, Global LEAP winners & $0.068(n=5)$ & $0.062(n=3)$ & $0.060(n=4)$ \\
Mean EEI, Global LEAP finalists & $0.074(n=2)$ & $0.085(n=10)$ & $0.077(n=11)$ \\
\hline
\end{tabular}

Unpublished data sourced from CLASP 
Table 4 Energy efficiency trends for all TV products tested by year

\begin{tabular}{lllll}
\hline Year & \multicolumn{3}{l}{ Energy efficiency index $\left(\mathrm{W} /\right.$ /n. $\left.^{2}\right)$ by year } \\
\cline { 2 - 5 } & $\begin{array}{l}\text { Mean, all } \\
\text { products }\end{array}$ & $\begin{array}{l}\text { Most } \\
\text { efficient }\end{array}$ & $\begin{array}{l}\text { Least } \\
\text { efficient }\end{array}$ & $\begin{array}{l}\text { EEI ratio, } \\
\text { highest to lowest }\end{array}$ \\
\hline $2014(n=7)$ & 0.070 & 0.042 & 0.116 & 2.5 \\
$2015(n=4)$ & 0.094 & 0.058 & 0.184 & 3.2 \\
$2016(n=36)$ & 0.113 & 0.046 & 0.227 & 5.0 \\
$2017(n=27)$ & 0.101 & 0.032 & 0.254 & 7.9 \\
\hline
\end{tabular}

Unpublished data sourced from CLASP markets; for example, Bertoldi et al. (2016) reported that a $25 \%$ reduction in the annual energy consumption of refrigerators and washing machines was seen between 2004 and 2014, partly as a result of the EU Ecodesign and Energy Labelling policy instruments. If similar instruments were applied to the off-grid market, this could bridge the gap in efficiency observed above. Park and Phadke (2017) also recommended that energy labels should be considered to further facilitate the adoption of efficient TVs in offgrid settings. The trends observed here could therefore provide valuable insights to stakeholders who may be involved in identifying products for

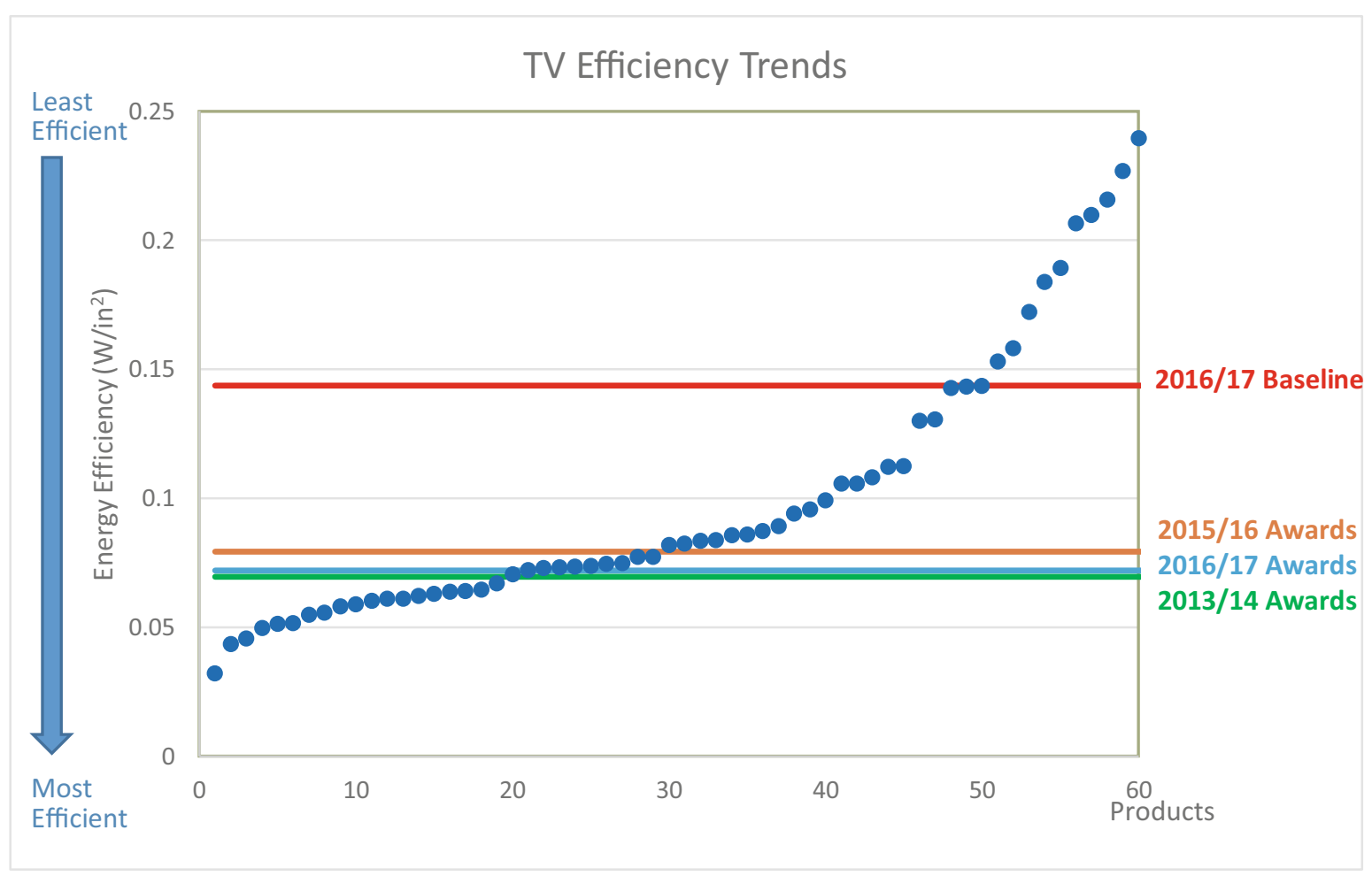

Fig. 2 TV efficiency trends, comparing average efficiency of baseline and awards products Unpublished data sourced from CLASP 
Fig. 3 TV efficiency and price distribution Unpublished data sourced from CLASP

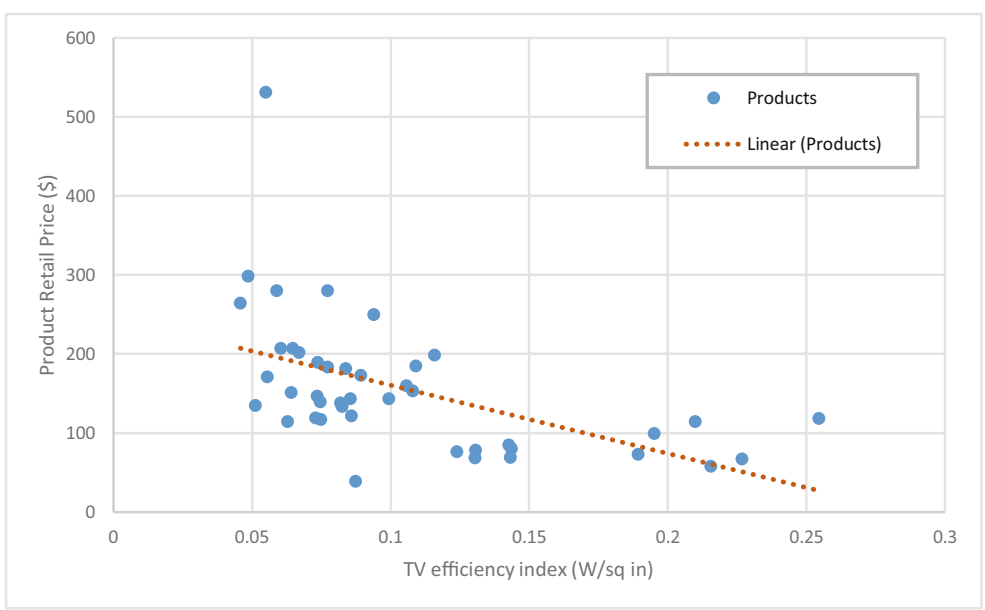

procurement, or who wish to understand how best to size solar systems and package appliances with their product offerings.

Cost trends For accurate price comparisons among differently sized TVs, the metric of cost per unit area of screen size (US dollars per square inch, or $\$ /$ in. ${ }^{2}$ ) was used. Cost data was available from market surveys as well as tests, and a correction factor ${ }^{14}$ was applied in cases where test samples were received directly from manufacturer warehouses to account for import duties, taxes and retailer markups. Figure 3 shows the correlation between TV price and efficiency.

The cost of off-grid TVs appears to be reducing over time (Table 5). While sample sizes presented here are relatively small, available price data of the tested products shows a clear reduction between 2014 and 2017. An assessment was also made of price differences between 2017 Global LEAP Award winners and finalists compared with other products tested that year. Again, while there are not many data points, the cost per unit area figure for the 2017 winners and finalists was $63 \%$ higher than baseline products, suggesting that better quality products may be subject to higher pricing.

Data from the market survey shows early cost trends for 2018 in the countries observed. The lowest priced product available in each country was below $\$ 0.40$ per square inch of screen size- to put this number into context, a $24-$ in. TV has a screen area of 246 in. $^{2}$ (at $16: 9$ aspect ratio), so at $\$ 0.40$ per in. ${ }^{2}$, this results in a

\footnotetext{
$\overline{14}$ The wholesale prices declared by manufacturers are multiplied by a factor of 1.8 to adjust for estimated taxes, duties, supply chain markups, etc.
}

price of $\$ 98.40$. TVs of this price are widely available in on-grid markets, suggesting the African TV market has not yet benefitted significantly from scale. The lowest cost to area ratio seen was for a TV in Uganda, of 0.18 this corresponded to a 29 -in. set sold for $\$ 65$ in Kampala. Table 6 showcases further country comparisons.

Median prices observed in each country were within a similar range to test samples from 2017. As testing to date for initiatives such as Global LEAP has given greater focus to models expected to be of higher quality and efficiency (and generally more expensive), relatively little is known about the performance of models at the lower end of the cost spectrum.

Comparison with TVs available in the on-grid market Various comparisons have been made between the energy-efficiency of DC, off-grid TVs and AC models, designed for on-grid use. Inherently, a DC TV should achieve higher efficiency than a similarly sized

Table 5 Year-on-year cost trends for TVs ${ }^{\mathrm{a}}$

\begin{tabular}{ll}
\hline Year & $\begin{array}{l}\text { Average cost per } \\
\text { screen size }\left(\$ / \text { in. }^{2}\right)\end{array}$ \\
\hline $2014(n=6)$ & 1.57 \\
$2016(n=30)$ & 1.00 \\
$2017(n=22)$ & 0.93 \\
$2016 / 17$ Global LEAP winners & 1.06 \\
$\quad$ and finalists $(n=15)$ & 0.65 \\
2017 non-winners and finalists $(n=7)$ & \\
a Sufficient pricing data was not available for 2015 and is therefore \\
excluded from this table
\end{tabular}


Table 6 Cost comparisons (in USD per unit screen size area) in various TV markets

\begin{tabular}{llll}
\hline Country & $\$ /$ in. $^{2}$-lowest & $\$ /$ in. $^{2}$-median & $\$ /$ in. $^{2}$ - highest \\
\hline Sierra Leone & 0.31 & 0.52 & 2.17 \\
Kenya & 0.33 & 0.64 & 1.57 \\
Uganda & 0.18 & 0.46 & 0.73 \\
Tanzania & 0.37 & 0.55 & 0.92 \\
\hline
\end{tabular}

Unpublished data sourced from CLASP

$\mathrm{AC}$ model, due to not requiring an AC-DC current conversion (other things being equal). Park and Phadke (2017) estimated that for AC TVs, the AC to DC conversion results in an estimated electricity loss of $5-15 \%$.

Another TV study by Park et al., (2017) reported that some TVs designed for the off-grid, developing world market were already on a par with on-grid TVs in terms of efficiency. The paper compared 18 AC TVs achieving the US ENERGY STAR "Most Efficient" rating (data for TVs from 15 to 24 in. from 2015), with TVs featured on Topten China (from 2015, for 32 in. sets), and TVs submitted to the 2013/2014 Global LEAP Awards (TVs between 15 and $23 \mathrm{in}$.) and found similar values for on-mode power consumption and efficiency, measured in Watts per square inch of screen size (it is noted that products may not be directly comparable, as default luminance settings and network features may have been different). The ENERGY STAR TVs were in the range of $0.06-0.11 \mathrm{~W} / \mathrm{in}^{2}$, the models on Topten China between 0.06 and $0.12 \mathrm{~W} /$ in. $^{2}$, and the off-grid sets in the range of $0.05-0.10 \mathrm{~W} / \mathrm{in}^{2}$.

For this paper, another comparison is made between TV test results from the Data Platform and manufacturers' declared energy label figures for $18 \mathrm{~A}+$ rated TVs taken from Topten UK (2018), ${ }^{15}$ which features best-in-class models on energy efficiency from the UK market.

Additionally, a comparison of luminance values was also conducted, with test data available for 66 off-grid TVs. Tests measured the luminance (in candela per meter-squared $\left.\left(\mathrm{cd} / \mathrm{m}^{2}\right)\right)$ in retail (default) mode. This was compared to data from 20 randomly selected TVs with screen size $\leq 40 \mathrm{in}$. tested under the ComplianTV Product Database $(2018)^{16}$ project. Luminous efficacy

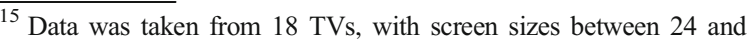
40 in.

${ }^{16}$ Data was taken from laboratory tests of 20 TVs, with screen sizes of $40 \mathrm{in.}$ and under, tested between 2013 and 2015.
}

data (in candela per meter-squared per Watt, or $\mathrm{cd} / \mathrm{m}^{2} /$ $\mathrm{W})$ were also compared to determine whether relatively low power requirements observed for off-grid TVs were a result of a lower screen brightness (Table 7).

The mean efficiency of on-grid TVs was seen to be higher (lower EEI) than that for off-grid TVs among which there is more variability and no established standardization, market surveillance, or formal policy instruments in place. However, an interesting comparison was seen when taking the 90th percentile EEI for both data sets: the most efficient off-grid TVs actually achieved a better efficiency figure than on-grid TVs.

The reason for this higher efficiency may be that some manufacturers design off-grid TVs to work at lower luminance, to operate at lower power, and maximize battery life. Comparing the luminance test data between the off and on-grid sets showed that the lowest off-grid TV in the range was operating at less than half the brightness of the lowest on-grid set tested by ComplianTV. This is expected, given that off-grid user would have different power management needs from an on-grid user. However, the median values from the two data sets were much closer (only $11 \%$ higher for on-grid sets), and the brightest off-grid TV was actually measured to have higher luminance than the brightest ongrid TV.

Table 7 Comparison of efficiency index and luminance measurements between off-grid TVs and on-grid TVs from the European market

\begin{tabular}{|c|c|c|}
\hline TVs & Off-grid test data & On-grid products \\
\hline \multicolumn{3}{|c|}{ Energy efficiency index (W/in. $\left.{ }^{2}\right)$} \\
\hline EEI (mean) & 0.083 & 0.071 \\
\hline EEI (90th percentile) & 0.051 & 0.066 \\
\hline \multicolumn{3}{|l|}{ Luminance $\left(\mathrm{cd} / \mathrm{m}^{2}\right)$} \\
\hline Lowest & 36 & 76 \\
\hline Median & 158 & 173 \\
\hline Highest & 425 & 299 \\
\hline \multicolumn{3}{|c|}{ Luminous efficacy $\left(\mathrm{cd} / \mathrm{m}^{2} / \mathrm{W}\right)$} \\
\hline Lowest & 3.93 & 3.45 \\
\hline Median & 12.1 & 6.11 \\
\hline Highest & 31.08 & 15.30 \\
\hline
\end{tabular}




\section{Key findings for off-grid TVs}

The energy efficiency of TVs for the off-grid market appears to be improving overall Test data showed an increasing EEI over the last 2 years of tests, both for best-in-class models and those in the mid-to higher ranges of the market on efficiency. There is less data available on TVs at the lower end of the efficiency range. The analysis suggests that there are still TVs available that are significantly less efficient than the top performers, but more testing needs to be done to establish what portion of the market these TVs actually account for.

The cost for off-grid TVs also appears to be on a downward trajectory Whether this is due more to a reduction in costs for manufacturers as the market becomes more established, or to increased demand, is currently unknown. Data suggests that better quality products are more expensive as a rule, and there are also comparatively cheaper products available, where little is known about their quality and efficiency.

More could be done to improve the accuracy of available reported data Testing showed that a significant proportion of TVs had lower power measurements than their rated values (see section entitled "Accuracy of claimed energy performance values"), and in the absence of standardized reporting metrics, there may be wide variation between suppliers as to what "rated" power actually refers to. When selecting an appropriate TV for use with a SHS, a difference of even $5 \mathrm{~W}$ on either side of an expected power consumption value can be a crucial factor for ensuring that the system provides sufficient electricity as expected to power the TV in question.

Off-grid and weak-grid fans

\section{Current state of the off-grid fan market}

Fans are becoming a critical part of thermal cooling solutions to address serious health issues caused by the rising temperatures in some of the most vulnerable developing countries. The World Health Organization (WHO) forecasts that nearly 100,000 deaths could be caused by heatwaves each year by 2030 (WHO, 2018). Without access to cooling energy services, consumers living in off- and weak-grid environments are exposed to the risks of over-heating during high temperature months. With air conditioners remaining out of reach for most households in rural markets, fans become an essential cooling solution that is currently far more affordable.

Climate is, as expected, a major determinant of relative demand for fans in off-grid markets. Off-grid consumers consider fans a necessity in regions with hot and humid climate conditions, such as South Asia. A 2017 survey of energy access professionals found that fans ranked the first and third among the most demanded appliances in Bangladesh and India, respectively (Global LEAP, 2017). In other off-grid markets, such as East Africa, the demand for off-grid fans is less prominent.

Despite the fact that product demand is limited to certain geographies, the off-grid fan market has the potential to grow exponentially. Estimates suggest annual spending on off-grid fan products in 2020 could reach USD \$500 million, if energy efficiency and design improvements are adopted more widely (Global LEAP, 2016).

\section{Off-grid fan data trends}

Test data is available for 55 fans, comprising table, pedestal, and ceiling models. The market survey provided data for 279 fans from Pakistan, India, Uganda, Kenya, and Tanzania, ${ }^{17}$ with the majority $(51 \%)$ observed in Pakistan, where higher demand exists compared to East Africa as described above.

Product specification observations The relative availability of data for different fan products obtained from market survey data is shown in Table 8 .

Little to no variability on product size was evident from market survey data, which did not provide any strong insights on consumer preference or design trends. Most table fans available were at least of 12-in. diameter. Pedestal fans seen were mainly in the 14-20-in. size bracket, with most ceiling fans sized over 42 in.

Where available, type of current was assessed for table and pedestal fans. DC fans appeared to be more widespread, accounting for $77 \%$ of all pedestal fans and

\footnotetext{
${ }^{17}$ The number of units found through the market surveys do not necessary represent or indicate the relative market size for fans in these markets. It is only indicating the available models and units identified through the survey.
} 
Table 8 Split of fans by type and size category from 2018 market survey data

\begin{tabular}{ll}
\hline Fan type & Number \\
\hline Small table fans (<12 in.) & 3 \\
Large table fans ( $\geq 12$ in.) & 39 \\
Table fans & 12 \\
Pedestal fans & 167 \\
Small ceiling fans $(<42$ in.) & 3 \\
Large ceiling fans $(\geq 42$ in.) & 47 \\
Other types & 8 \\
Total & 279 \\
\hline
\end{tabular}

Unpublished data sourced from CLASP

$57 \%$ of all table fans seen in the survey. Data on whether these fans employed a brushed or brushless DC motor was not available. Brushed DC motors tend to be less durable due to increased motor failure from brushes wearing down, but brushless technology is often more expensive, and therefore cost-inhibitive in most off-grid markets. However, permanent-magnet, brushless DC (BLDC) motor-powered fans have been found to achieve higher efficiency than their AC, inductionmotor counterparts, which remain prevalent in on-grid markets where optimizing efficiency is less of a concern.

Phadke et al. (2015) reported that BLDC technology can result in an efficiency improvement of around 50\% over AC technology for ceiling fans. Beyond the motor, improved blade design can increase ceiling fan efficiency by around $15 \%$ (Sathaye et al., 2012). Various approaches have addressed this aspect of design to improve efficiency, such as the use of aerodynamic attachments, as well as twisted, tapered (TT) blades (Shah et al., 2015). While there appears to be scope for improving the efficiency of fans for off-grid settings through these technologies, studies show that the cost to incorporate these features can be relatively high without scale in the market. Data reported by Shah et al. estimate that incorporating a BLDC motor into a fan would be expected to increase the manufacturing cost by $\$ 10.50$ on average, while adding efficient blade technology would increase the average incremental manufacturing cost by $\$ 3.50$.

In fact, despite BLDC fans showing the highest estimated efficiency improvement, Shah et al. (2015) proposed that improving the performance of $\mathrm{AC}$ induction motors was actually a more cost-effective efficiency measure, given the lower cost (around \$1.50), despite a lower reduction in power consumption (estimated at $36 \%$, compared to $50 \%$ for a BLDC against a baseline $\mathrm{AC}$ motor, with data from the Indian market). However, this cost estimation did not take into account aspects such as reduced SHS capacity or the need to use an inverter. Therefore, to enable users to benefit from the savings offered by BLDC motors as the best available technology, there remains a need for cost reduction, and to be able to weigh this against the efficiency improvement. The Data Platform provides a valuable resource to track this market development by presenting extensive performance and cost data.

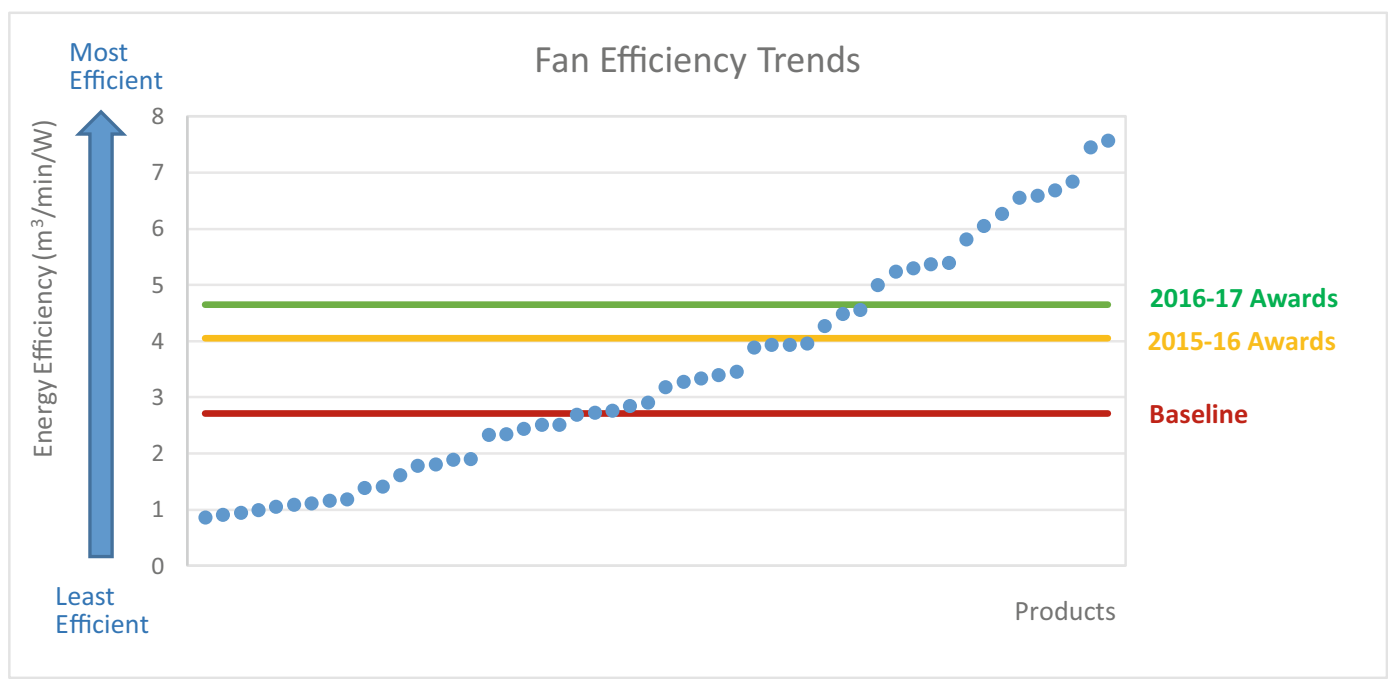

Fig. 4 Fan efficiency trends, comparing average efficiency of baseline and awards products Unpublished data sourced from CLASP 
Table 9 Lowest and highest of energy efficiency index values for table, pedestal, and ceiling fans

\begin{tabular}{llll}
\hline & \multicolumn{2}{l}{ Energy efficiency index, $\mathrm{m}^{3} / \mathrm{min} / \mathrm{W}$} \\
\cline { 2 - 4 } Product type & Lowest & Median & Highest \\
\hline Table fans $(n=17)$ & 0.87 & 2.12 & 4.28 \\
Pedestal fans $(n=11)$ & 1.18 & 2.86 & 4.49 \\
Ceiling fans $(n=15)$ & 4.59 & 6.09 & 7.61 \\
\hline
\end{tabular}

Unpublished data sourced from CLASP

Efficiency trends Fan efficiency was assessed and compared using the metric of meters-cubed per minute of air delivered per Watt of input power $\left(\mathrm{m}^{3} / \mathrm{min} / \mathrm{W}\right.$, denoted as the EEI). Data suggests that fan efficiency is improving over time, but the range in efficiency varies significantly across the market (Fig. 4).

For this assessment, we split the data by product type between pedestal, table, and ceiling fans. All tests to determine EEI were completed between April 2016 and February 2018 (Table 9). For the table and pedestal fans, the efficiency range is larger than for ceiling fans, with the most efficient product delivering around four times the volume of air per minute per Watt of input power compared to the least efficient product.

An assessment of the efficiency of DC versus AC fans was also conducted for table and pedestal variants (Table 10). While the number of data points available is not large, test data does appear to suggest that DC fans are currently achieving better efficiency than AC fans. Factoring in product specifications from market surveys, AC fans generally operate at higher levels of power. This is a key consideration when weighing cost and power usage (including whether to use DC

Table 10 Range of measured values for input power for DC and AC fans

\begin{tabular}{lllll}
\hline & & \multicolumn{3}{c}{ Max speed input power $(\mathrm{W})$} \\
\hline Table fans & Mean EEI & Low & Median & High \\
DC $(n=20)$ & 2.47 & 1.85 & 9.60 & 30.57 \\
AC $(n=4)$ & 1.23 & 11.39 & 12.19 & 52.11 \\
Pedestal fans & Mean EEI & Low & Median & High \\
DC $(n=10)$ & 3.19 & 6.89 & 11.22 & 28.08 \\
AC $(n=4)$ & 1.77 & 12.97 & 26.62 & 41.54 \\
\hline
\end{tabular}

Unpublished data sourced from CLASP
Table 11 Price averages for fans observed in 2018 market survey

\begin{tabular}{lcl}
\hline Type of fans & Count & Average price \\
\hline DC pedestal & 129 & $\$ 26.58$ \\
AC or AC/DC pedestal & 38 & $\$ 41.05$ \\
DC table & 34 & $\$ 16.99$ \\
AC or AC/DC table & 18 & $\$ 38.96$ \\
\hline
\end{tabular}

Unpublished data sourced from CLASP

appliances or AC models with an inverter) for product selection to be paired with any given distributed energy solution.

Despite the fact that DC fans seem to be the obvious choice, it is also important to note that interviews with off-grid fan suppliers suggest that efficiency is not the whole picture for a given off-grid environment. As an appliance with moving parts, there is potential for a fan to break down early in its lifetime. Product quality and durability, and after-sales services provided by distributors, are also important considerations for off-grid consumers when making a purchase decision.

Cost trends Market survey data was used to assess the current state of play on cost. AC fans were seen to be more expensive than DC fans sampled (Table 11).

The relative presence of table and pedestal fans by country was also assessed. The fan markets in Pakistan and India are considered more advanced than in East Africa, with overall demand being consistently higher (Table 12).

Price data was also available for samples tested; this

Table 12 Price trends by country for table and pedestal fans, from 2018 market survey

\begin{tabular}{lcc}
\hline Country & Sample size & Average cost \\
\hline $\begin{array}{l}\text { Pedestal fans } \\
\text { Pakistan }\end{array}$ & 106 & $\$ 26.07$ \\
India & 15 & $\$ 15.73$ \\
Kenya & 14 & $\$ 42.03$ \\
Tanzania & 18 & $\$ 29.09$ \\
Uganda & 11 & $\$ 27.30$ \\
Table fans & & \\
Pakistan & 11 & $\$ 34.49$ \\
India & 34 & $\$ 10.28$ \\
\hline
\end{tabular}

Unpublished data sourced from CLASP 


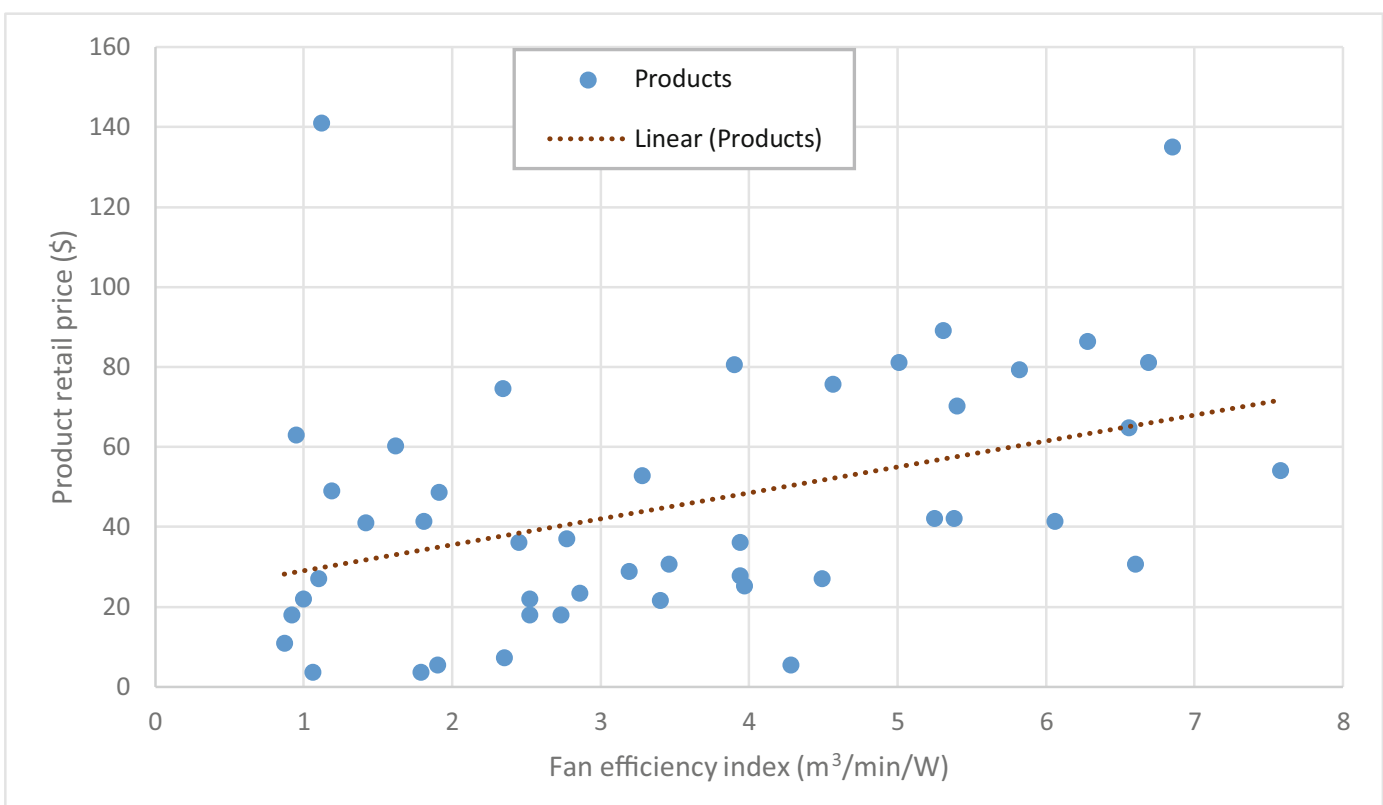

Fig. 5 Fan efficiency and retail price distribution Unpublished data sourced from CLASP

shows some correlation between higher EEI values and cost, although not as marked a trend as was seen for TVs (Fig. 5).

Comparison with fans in the on-grid market Assessment of fans sought to compare the size and energy consumption trends between off- and ongrid markets (Table 13). Data from off-grid model tests was compared with manufacturer specifications of ongrid table and pedestal fans listed on Topten Switzerland (2018). ${ }^{18}$ Test data appears to show higher levels of efficiency for off-grid fans at both average values and at the top of the range; however, little is known on their lifetime and durability. In terms of size trends from the data, the median-sized off-grid fan appears to be smaller and is rated as using significantly less power $(64 \%$ lower for table fans and $31 \%$ lower for pedestal fans, respectively) than in the on-grid European market.

\section{Key findings for off-grid fans}

As with TVs, test data suggests a relatively high difference between the most and least efficient products on the market, and in the absence of extensive, accurate, and

\footnotetext{
${ }_{18}$ Data taken from 39 on-grid table and 29 pedestal fans featured on Topten Switzerland.
}

accessible data, procuring a fan that is both efficient and of suitable quality may be difficult. Little can be gleaned from test data on product quality and lifetime-while

Table 13 Comparisons of energy efficiency index, size, and rated power input between off-grid and on-grid fans

Table fans

$$
\begin{aligned}
& \text { Off-grid test data On-grid products } \\
& (n=17) \quad(n=39)
\end{aligned}
$$

Energy efficiency index

$\begin{array}{lll}\text { EEI (mean) } & 2.04 & 1.00 \\ \text { EEI (90th percentile) } & 3.93 & 1.27\end{array}$

Size

Median size (inches) 11.6

Power

Median rated power input (W)

Pedestal fans

14.4

34.4

Off-grid test data $(n=11)$

On-grid products

Energy efficiency index

EEI (mean)

2.68

1.26

EEI (90th percentile)

3.97

1.61

Size

Median size (inches) $\quad 15.20$

18.60

Power

Median rated power $\quad 17.50$

46.80

.00
.27
3.95
4.4
$(n=29)$
.26
.61
8.60
6.80

Unpublished data sourced from CLASP 
Global LEAP testing does include durability tests, motor lifetime in general use is a key aspect of product design that is not assessed in the Global LEAP test method and therefore excluded from this analysis. Best available technology in relation to efficiency has been identified in the studies mentioned above, but test and market survey data shows a range of technology types are available. More aligned best-practice around design for efficiency, incorporating the optimal combination of product features detailed above (BLDC motor, improved blade design), should result in closing the gap between the most and least efficient products, and greater market scale, in future.

The World Bank's Lighting Global Quality Standards ${ }^{19}$ incorporated quality and durability requirements for pico-PV and SHS kits have been adopted by a number of East African countries, such as Kenya, Rwanda, Ethiopia, and Tanzania, to eliminate lowquality products entering the market. Similar policy approach that focuses on quality and durability requirements can be applied to off-grid fans.

The cost of fans appears to be a function of the maturity of the product market. Pakistan and India have more developed markets for fans than in East Africa where demand is lower, and as a result, pricing is generally lower. Less historical pricing data exists for fans than for TVs; therefore, current figures may only be able to provide a baseline; however, existing data do suggest that the fan market could further benefit from scale and commoditization.

A fairly favorable comparison was seen between offgrid fans and their on-grid counterparts on efficiency. However, without accompanying standards or quality assurance frameworks, there is not sufficient assurance on product lifetime and quality across the board.

\section{Off-grid and weak-grid refrigerators}

\section{Current state of the refrigerator market}

Refrigerators hold unique potential to unlock economic and social progress for the billions of un- and underelectrified people globally. Consumers living in off-grid and weak-grid communities have a particularly high need for refrigeration to address food storage challenges. Lack of access to cold chain technology results in pre-market losses of up to $40 \%$ of food produced in

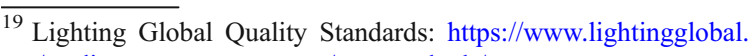
org/quality-assurance-program/our-standards/
}

the developing world, according to the UN's Food and Agriculture Organization (FAO, 2018).

The market for refrigeration products explicitly designed for use in off- and weak-grid settings is nascent, and the penetration of refrigerators in developing countries remains extremely low: overall market penetration is below $40 \%$ in Nigeria and 30\% in India. Rural market penetration is even lower, just $6 \%$ in Bangladesh (the world's largest national off-grid market) and $1 \%$ in Kenya (Global LEAP, 2016). This low penetration rate is due in large to the lack of off-grid appropriate, costeffective refrigerators. Conventional AC refrigerators typically found in retail markets require a significant amount of power, which makes them incompatible with intermittent grid connections or the limited amount of electricity provided by distributed energy systems (Market Baseline Performance Testing for Off-Grid \& WeakGrid Refrigerators, 2018). In order to be viable in offgrid settings and suitable for rural customers, refrigerators must become considerably smaller, cheaper, and run on far less energy than most conventional products.

Despite low penetration rates, latent demand for refrigerators is significant. Global LEAP research estimates that current annual spending on refrigerators by off- and weak-grid households is approximately $\$ 75$ million. If efficient, appropriately priced products become accessible to all households with the purchasing power to buy a refrigerator, spending could increase to $\$ 1.1$ billion by 2020 - a $38 \%$ compound annual growth rate-despite lower per unit costs (Global LEAP, 2016).

\section{Off-grid refrigerator data trends}

Product characteristics Fifty-seven different off-grid refrigerators were identified and procured through online marketplaces such as Alibaba ${ }^{20}$ and Amazon ${ }^{21}$; directly from manufacturers and distributors; and through field agents in key off-grid markets. These products underwent testing in accredited laboratories according to the Global LEAP Off-Grid Refrigerator Test Method ( 2018) to evaluate their energy performance, durability, and off-grid appropriateness.

Overall, the two primary types of refrigerators sold in the off-grid markets are identified as (1) standing or topopening refrigerators that have one fresh food

\footnotetext{
${ }^{20}$ Alibaba: https://www.alibaba.com/

21 Amazon: https://www.amazon.com/
} 
Table 14 Refrigerator size distribution

\begin{tabular}{ll}
\hline Refrigerators $(n=25)$ & $\begin{array}{l}\text { Refrigerator-freezer combination units } \\
(n=32)\end{array}$
\end{tabular}

\begin{tabular}{lrlr}
\hline Small $(\leq 50 \mathrm{~L})$ & 7 Small $(\leq 100 \mathrm{~L})$ & 10 \\
Medium $(51-100 \mathrm{~L})$ & 7 R-F medium $(101-200 \mathrm{~L})$ & 14 \\
R large $(100+\mathrm{L})$ & 11 & R-F medium $(101-200 \mathrm{~L})$ & 8
\end{tabular}

Unpublished data sourced from CLASP

compartment, ${ }^{22}$ and (2) refrigerator-freezer combination units $^{23}$ that have one fresh food compartment and one freezer compartment.

The average size of off-grid refrigerators is smaller compared to the traditional on-grid refrigerator market. The capacity of off-grid refrigerators found in the market in 2016-2017 averages about $130 \mathrm{~L}$, with the average capacity of refrigerator-freezer combination units being $27 \%$ larger than refrigerators. The most common product size for refrigerators is between 50 and $99 \mathrm{~L}$, and for refrigerator-freezer combination units between 100 and $149 \mathrm{~L}$ (Table 14).

Efficiency trends To enable a comparison of refrigerators and refrigerator-freezers across all sizes, a metric of daily energy consumed per surface area of the refrigerator, kilo-Watt-hours per meter-squared $\left(\mathrm{kWh} / \mathrm{m}^{2}\right)$ (Harrington 2015), ${ }^{24}$ was used for the analysis, defined in this paper as the EEI.

The analysis below compares the efficiency of refrigerators that were sampled from retail markets, defined as "baseline" products, and the Winners and Finalists "Awards" products that were identified by the 20162017 Global LEAP Awards Competition for Off-Grid Refrigerators (Global LEAP, 2018a. On average, the

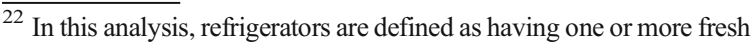
food compartments for the storage and preservation of unfrozen food and beverages, where the average storage temperature is at $4{ }^{\circ} \mathrm{C}$. Another common type of refrigerator has one or more compartments that can either be used as a refrigerator or a freezer by adjusting the thermostat control. In the case of Global LEAP Awards, this type of product is tested as a refrigerator.

${ }^{23}$ Refrigerator-freezer combination units have a combination of at least one fresh food and at least one freezer compartment, where the storage temperature is not warmer than $-18^{\circ} \mathrm{C}$.

${ }^{24} \mathrm{In}$ this analysis, energy consumed per surface area $\left(\mathrm{kWh} / \mathrm{m}^{2}\right)$ is used instead of energy per unit volume $\left(\mathrm{kWh} / \mathrm{m}^{3}\right)$ to enable comparison of refrigerators and refrigerator-freezers of various sizes. Refrigerator heat gain is dictated by the surface area and not volume. The surface area is calculated as volume to the power 0.67 . The algorithm has reduced some of the previous problems of size bias in favor of larger cabinets (Harrington 2015).
}

efficiency of "baseline" products is $0.0449 \mathrm{kWh} / \mathrm{m}^{2}$, while the average efficiency is 0.0285 for Global LEAP Awards finalists and 0.0196 for Awards winnersrepresenting a 36 and a $56 \%$ efficiency improvement compared to the baseline average, respectively.

The data indicates that there is a significant gap in efficiency between baseline products and the bestperforming products in the market (Fig. 6). Based on the test data, the efficiency of the tested products varies significantly. The worst-performing refrigerator in this dataset, a 35-L refrigerator, uses 19 times more energy per surface area than the most efficient refrigerator tested, a 166-L refrigerator.

Off-grid and weak-grid households are energyconstrained, and the analysis also indicates that most of the "baseline" refrigerators found in the retail market consume more than $1.5 \mathrm{kWh}$ per day-drawing too much energy to be cost-effectively powered by an SHS. In order to be viable in off-grid settings and suitable for off-grid customers, therefore, refrigerators must consume considerably less electricity.

Cost trends Off-grid and weak-grid consumers are pricesensitive, especially for larger appliances considered as significant "investments" such as refrigerators. However, limited research has been done to date to understand consumers' willingness and ability to pay. The market data collection effort by CLASP in 2016 provides a first glimpse into off-grid refrigerator costs in the retail markets.

The analysis shows that the retail price of off-grid refrigerators varies significantly within each product type and size category but the average price slightly correlates with product size. Figure 7 shows the minimum to maximum price points within each size category, as well as the average price points. The refrigerators that have the highest retail price tend to be specialized off-grid refrigerators that are either designed to be used as a vaccine refrigerator, or use phase-change materials (PCMs) - a new cooling technology that uses water or other chemical substances to absorb and release thermal energy as its melting and freezing (Tulapurkar et al., 2010).

Refrigerators with PCMs typically have better thermal performance, enabling cooling within the required temperature range for a longer period of time, even without power supply. However, there are only a few off-grid refrigerators in the market currently using this technology, and the retail price of this type of refrigerator is much higher compared to conventional vapor-compressor refrigerators within the same size categories. 


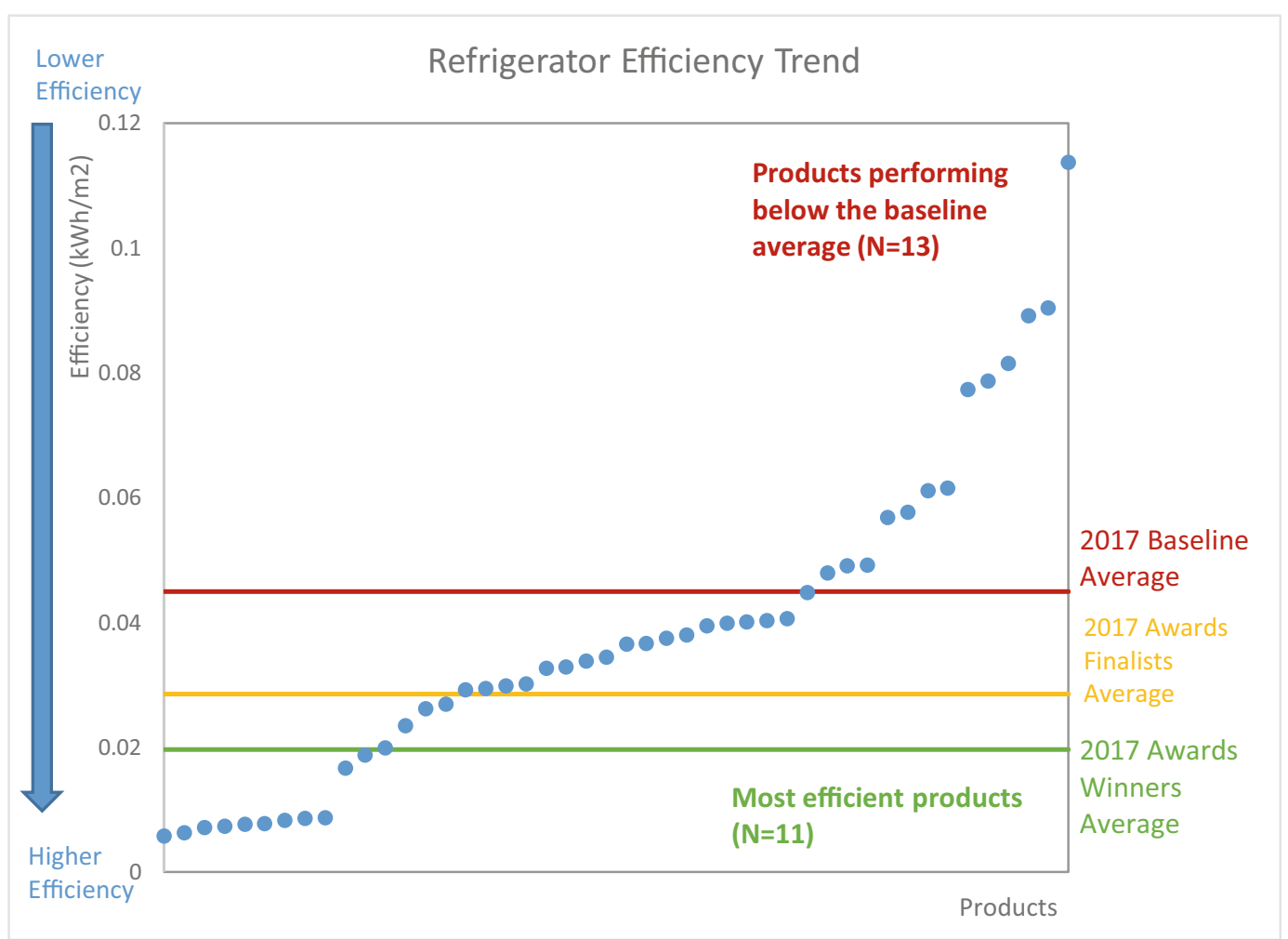

Fig. 6 Refrigerator energy efficiency trends - comparing average efficiency of baseline and awards products Unpublished data sourced from CLASP

The retail price of off-grid refrigerators is seen to correlate with the product size. In contrast to on-grid refrigerators - whose pricing is often influenced by the number of added features, e.g., Wi-Fi-enabled, customizable temperature zones, etc., off-grid refrigerator designs tend to be simplified and thus the retail price is more closely associated with product size. For both refrigerators and refrigerator-freezer combination units, products that are larger in capacity tend to be more expensive (Table 15).

Given unique off-grid energy market dynamics, striking a balance between efficiency and price is a key business consideration for market actors. The analysis below provides initial insights on dynamics between price and efficiency for refrigerators. Because of the retail pricing of refrigerators varies significantly, in Fig. 8, three outliers representing the highest retail prices (above \$1800) were removed to enable a more accurate observation of general price and efficiency trends. The analysis indicated that there is a correlation between price and efficiency, with more efficient products costing more on average.

\section{Additional energy performance discussions}

Daily energy consumption at various ambient temperatures Ambient air temperature is a key driver of a refrigerator's energy consumption, but limited data exists comparing off-grid refrigerators' performance at various ambient temperatures. Multiple climates can be observed in off-grid regions, even within the same continent or country. For example, in Pakistan, the weather varies drastically by region - the summer in the South is often hot and humid with $50{ }^{\circ} \mathrm{C}$ heat waves (Astor, 2018), whereas the Northern winters can reach subzero temperatures.

Given the diverse climate zones observed in off-grid markets, off-grid refrigerator testing is conducted in various ambient temperatures to demonstrate its impact on refrigerator performance. Based on the Off-Grid Refrigerator Test Method, the average daily energy consumption, defined as kilowatt hour per day, is measured at three ambient temperatures: 16,32 , and $43^{\circ} \mathrm{C}$ (Global LEAP, 2018b). 


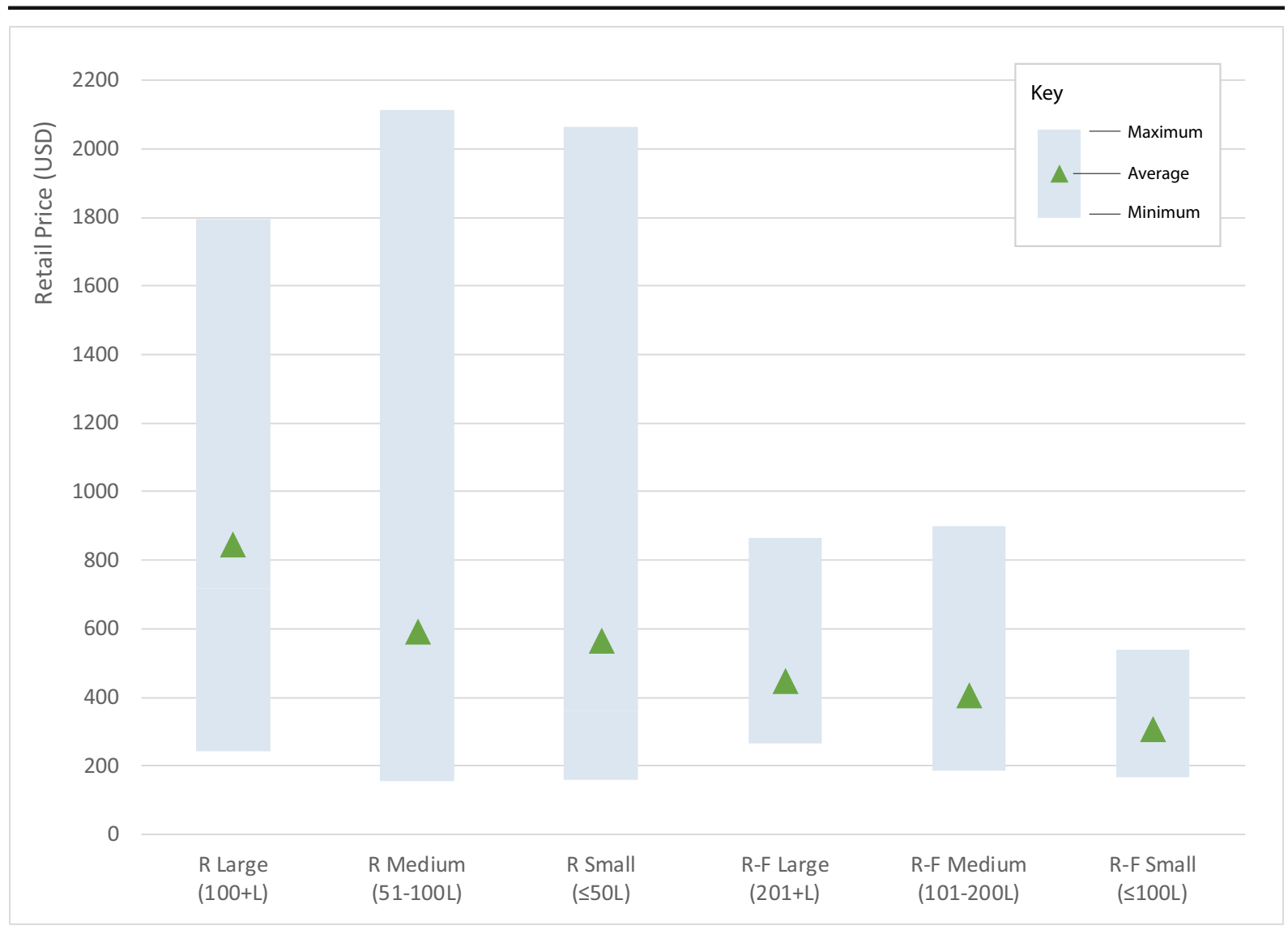

Fig. 7 Minimum, average, and maximum refrigerator retail price by type and size Unpublished data sourced from CLASP

The effect of ambient temperatures on refrigerator energy consumption is well-known. A research in 2009 reviewed test data of 100 grid-connected refrigerators and demonstrated the energy consumption measured at an ambient temperature of $30^{\circ} \mathrm{C}$ roughly doubles the value measured at $15{ }^{\circ} \mathrm{C}$ ambient temperature (Harrington, 2009). For off-grid refrigerators, the same effect is observed. The average daily energy consumption at $32{ }^{\circ} \mathrm{C}$ was $0.739 \mathrm{kWh} /$ day, while the average daily energy consumption at $43{ }^{\circ} \mathrm{C}$ was $1.254 \mathrm{kWh} /$ day-a $70 \%$ increase.

Autonomy Autonomy - the ability to keep a sealed refrigerator compartment cool without input of power-is one
Table 15 Average retail price by refrigerator type and size

Unpublished data sourced from CLASP

\begin{tabular}{llll}
\hline Refrigerator type & Size & $\begin{array}{l}\text { Number of } \\
\text { products }\end{array}$ & $\begin{array}{l}\text { Average of } \\
\text { product retail price }\end{array}$ \\
\hline Refrigerators & R large (100+ L) & 11 & $\$ 845$ \\
& R medium (51-100 L) & 7 & $\$ 593$ \\
& R small ( $\leq 50 \mathrm{~L})$ & 7 & $\$ 566$ \\
Refrigerator-freezer & R-F large $(201+\mathrm{L})$ & 8 & $\$ 447$ \\
combination units & R-F medium $(101-200 \mathrm{~L})$ & 14 & $\$ 407$ \\
& R-F small $(\leq 100 \mathrm{~L})$ & 10 & $\$ 308$ \\
\hline
\end{tabular}




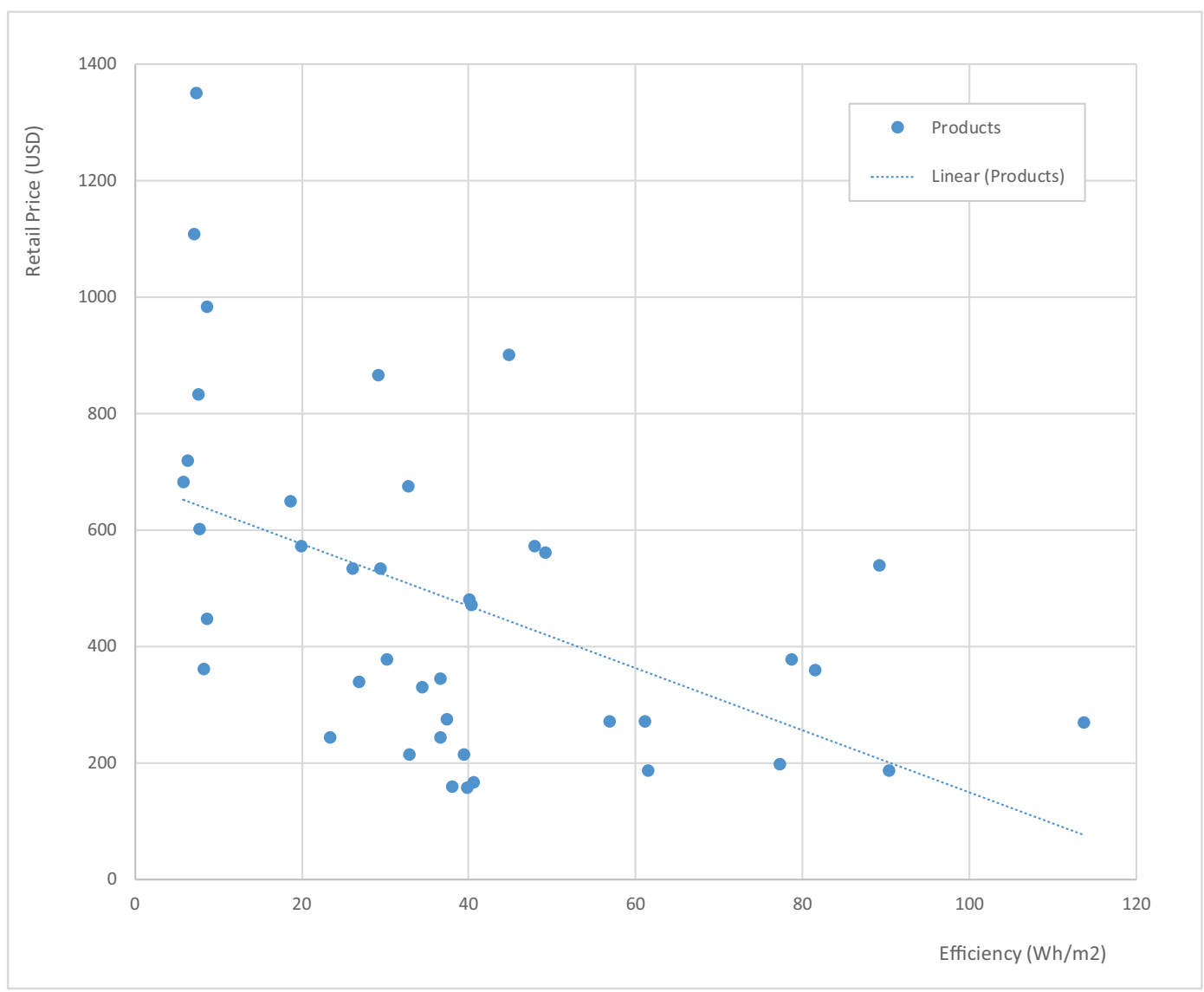

Fig. 8 Refrigerator efficiency and retail price distribution Unpublished data sourced from CLASP

of the refrigerator characteristics most valued by consumers who live in off- and weak-grid environments with highly constrained and/or intermittent electricity supply. The autonomy testing measures the number of hours it takes a product's internal compartment temperature to rise from 4 to $12{ }^{\circ} \mathrm{C}$ with no external power supply.

For all products tested, autonomy ranges from $0.38 \mathrm{~h}$ being the lowest, to $133 \mathrm{~h}$ being the highest. The products that can hold $133 \mathrm{~h}$ use PCM technology as discussed in the previous section. If we were to exclude that particular refrigerator model, the average value of autonomy is seen to be approximately $1.7 \mathrm{~h}$ (Fig. 9).

On average, refrigerators outperformed refrigeratorfreezer combination units in autonomy testing. The average refrigerator autonomy performance is almost twice as long as that of combination units.

Comparison with refrigerators in the on-grid market The average efficiency of off-grid refrigerators was compared with the most efficient on-grid refrigerators - products that carry $\mathrm{A}+++$ or $\mathrm{A}++$ labels based on the European energy labeling regulation (European Commission, n.d.) - in similar types and sizes.

Table 16 compares the energy efficiency metric, daily energy consumption per unit surface area, of on-grid and off-grid refrigerators. Data indicates that there are significant efficiency gaps between on-grid and off-grid products. On average, off-grid refrigerators consume three to five time more than $\mathrm{A}+++\mathrm{A}++$ on-grid refrigerators. It is notable that the best available off-grid refrigerator has the smallest efficiency gap with its ongrid counterpart. There are certainly efficiency improvement opportunities for off-grid refrigerators. It is estimated that if a series of efficiency improvements are incorporated in the design, such as using higher efficiency compressors, increasing insulation thickness, optimizing thermostatic control, etc., a refrigerator could save between 9 and $85 \%$ of energy compared to its base model (Shah et al., 2014). 
Fig. 9 Autonomy (in average hours) by refrigerator type Unpublished data sourced from CLASP
Refrigerator

Refrigerator-freezer combination unit

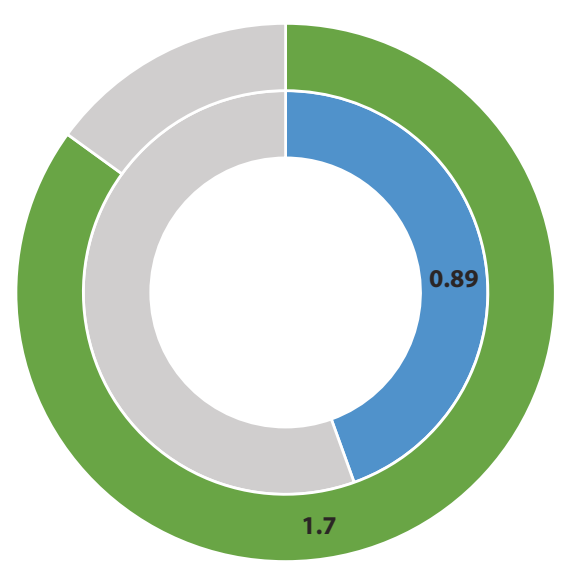

\section{Key findings for off-grid refrigerators}

The off-grid refrigerator market is still nascent. Both product availability and options are very limited in rural, off-grid areas. For example, an initial market survey in Zanzibar, Tanzania-where $80 \%$ of the population do not have access to municipal power and rely on off-grid technologies - showed there is no existing refrigerator stock in the solar shops. Refrigerators are made available only when a consumer puts in an order.

For refrigerators that are currently available in offgrid markets, the data indicates that the daily energy consumption is high - an average of $0.739 \mathrm{kWh}$ per day, measured in the test laboratory at $32{ }^{\circ} \mathrm{C}$ ambient temperature. To use a SHS to power an average off-grid refrigerator in an optimal scenario would require a 200W peak capacity (Wp) solar panel with a 160 -amperehour $(\mathrm{Ah})$ standard lithium iron phosphate $\left(\mathrm{LiFePO}_{4}\right)$ battery. ${ }^{25}$ Based on the 2018 Off-Grid Solar Market Trends Report (IFC 2018), roughly $1 \%$ of the addressable market households can afford 50-100 Wp SHS kits. This indicates that off-grid refrigerators need to become much more efficient and consume less than $0.4 \mathrm{kWh}$ a day to be supported by a $100-\mathrm{Wp}$ solar system. $^{26}$

In addition to energy consumption, the cost of refrigerators is also a critical barrier inhibiting more off-grid

\footnotetext{
$\overline{25}$ Based on a theoretical calculation.

${ }^{26}$ Based on a theoretical calculation.
}

consumers' getting access to refrigerators. The cost of tested refrigerators ranges roughly from $\$ 300$ on the low-end to $\$ 1500$ on the high-end. Consumer financing such as monthly installments or adapting Pay-As-YouGo (PAYG) options for off-grid refrigerators could improve the appliance's affordability.

The pricing of refrigerators varies significantly, and a higher price is not always associated with better energy performance or quality. Data indicates that products with similar energy performance could have up to 3.6 times difference in terms of pricing. The pricing inconsistency, coupled with the lack of clear performance specification declared on product nameplates and packaging, makes it challenging for consumers

Table 16 Efficiency $\left(\mathrm{kWh} / \mathrm{day} / \mathrm{m}^{2}\right)$ comparison between on-grid and off-grid refrigerators

\begin{tabular}{|c|c|c|c|}
\hline & Off-grid $^{\mathrm{a}}$ & On-grid ${ }^{b}$ & Difference $(\%)$ \\
\hline \multicolumn{4}{|l|}{ Refrigerators } \\
\hline Mean EEI & 0.0347 & 0.0089 & $290 \%$ \\
\hline Highest EEI & 0.0058 & 0.0041 & $41 \%$ \\
\hline Lowest EEI & 0.0904 & 0.0158 & $472 \%$ \\
\hline \multicolumn{4}{|c|}{ Refrigerator-freezer combination units } \\
\hline Mean EEI & 0.0511 & 0.0117 & $337 \%$ \\
\hline Highest EEI & 0.0269 & 0.0074 & $264 \%$ \\
\hline Lowest EEI & 0.1137 & 0.0172 & $561 \%$ \\
\hline
\end{tabular}


and distributors to make an informed decision based on price and efficiency considerations.

Programs such as quality assurance frameworks that require product manufacturers to clearly report energy performance on consumer-facing materials, such as product packaging, product nameplate, and user manuals, would help buyers make better and more informed purchase decisions for all off-grid appropriate products.

\section{Case study: field vs. lab testing results from an off-grid refrigerator pilot in Tanzania}

Background

Devergy, ${ }^{27}$ one of the leading companies in the minigrid sector with significant impact to date, having reached over 20 thousand people in Tanzania with energy services, branched out to include off-grid appropriate refrigerators as part of their business model in March 2018.

In the discovery phase, Devergy installed seven refrigerator units from a well-known off-grid refrigerator brand on several Devergy DC-based mini-grids in the Rukwa region of West Tanzania. While sourcing an appropriate refrigerator, Devergy referenced refrigerator test data from the Global LEAP Awards baseline testing for refrigerators, ${ }^{28}$ as well as taking into account initial assessments of the nominated refrigerators among the first-ever Global LEAP Awards for off-grid refrigerators. Devergy selected refrigerator units based on this preliminary data, as well as the name recognition of the refrigerator brand. The product in question was eventually recognized as one of the Finalists of the 2017 Global LEAP Awards Buyer's Guide (Global LEAP, 2018a).

As importing refrigerators to Tanzania is a complicated and difficult process, Devergy decided to select a model that is currently available in the Tanzanian market. They started their pilot with one brand and type of refrigerator to be tested across their different mini-grid locations to prove the business model and system appropriateness, before launching products at a larger commercial scale.

\footnotetext{
${ }^{27}$ Devergy: https://devergy.com/

${ }^{28}$ Market Baseline Performance Testing for Off-Grid \& Weak-Grid Refrigerators: http://www.efficiencyforaccess.org/assets/MarketBaseline-Report-Off-Grid-Refrigerators-May2018.pdf refrigerationresearch.html
}

Methodology

The seven refrigerators installed by Devergy all have different operation times and dates. The oldest one, set up on March 1, 2018, has been running continuously since its installation, and generating excellent revenues for the local entrepreneur.

Devergy's off-grid refrigerator field testing focuses on two aspects: technical feasibility and consumer profitability. In the assessment of sizing each system to support a refrigerator, the average energy consumption per day was the main - and in most cases the onlyparameter used. Unless exactly how much energy each refrigerator is consuming can be determined, it is hard to accurately size a system to support them accordingly. In the assessment of the profitability of each refrigerator, the sales made by each entrepreneur were monitored item by item. The revenue is calculated as overall profit on the products sold, not taking into account the cost of the refrigerator installation, or the energy costs associated with running the refrigerator.

Based on these initial assessments, Devergy installed three "enboxes" (energy box) with two $95 \mathrm{~W}$ solar panels per box (a total of $570 \mathrm{~W}$ ) as well as a battery pack of $750 \mathrm{Wh}$ with $50 \%$ discharge. This setup is oversized by a third-Devergy is able to switch off one of the three battery packs remotely, and have observed that the remaining setup is enough to cover the additional power requirements of the refrigerator, which can therefore work with only four solar panels at a total of $380 \mathrm{~W}$ with a 500 -Wh battery pack.

Devergy continues to collect performance, energy usage, and sales revenue data on a daily basis for all installed refrigerators.

\section{Findings}

\section{Performance and technical considerations}

A look at energy use data recorded by Devergy in May 2018 shows that the daily energy consumption measured during field testing is considerably higher than the lab-tested results. ${ }^{29}$ The manufacturer's product specification sheet claims the refrigerator would, in the worst-case scenario (in $32^{\circ} \mathrm{C}$ heat and on freezer mode), consume $440 \mathrm{Wh}$ per day, whereas field data shows the refrigerator to consistently oscillate between 1000 and

\footnotetext{
${ }^{29}$ Devergy proprietary data, shared during the case study interview.
} 
$1500 \mathrm{Wh}$ per day for the duration of the measurement (an entire month).

Devergy has also reported two key technical issues with off-grid refrigerator performance in the field, concerning the cooling capacity and compressor on/off cycles:

(1) In terms of cooling capacity, the refrigerators installed in the field are not reaching the freezing point. One refrigerator was installed at a local store whose primary business is selling cool beverages to customers. It turned out that cool beverages have extremely high demand, and the entrepreneur is constantly filling up the refrigerator with roomtemperature drink bottles, such that within a full daily cycle, the fridge is completely emptied of previously refrigerated items, sometimes multiple times. The internal temperature, measured by a proxy of the entrepreneur, qualitatively shows the bottles are not being cooled enough.

(2) In normal operating conditions, when a refrigerator is turned on, it senses the ambient temperature, starts the compressor, and cools the refrigerator chamber(s) down to the desirable target temperature. Once the temperature of the chamber goes below a set point, the compressor stops. In the field, however, the compressor never stops, even outside working hours where the refrigerator contents are being replenished. Devergy monitoring has shown that the compressor in each of the seven refrigerators keeps going constantly 24/7, which leads to high energy consumption and shortens the overall life of the refrigerator drastically.

Despite these technical challenges, the entrepreneur still considers it a good fridge, but acknowledges that it is using a lot of energy to keep up.

This is a concrete example of the importance of having both lab testing and field testing data for offgrid appropriate appliances, as the energy consumption measurements in a lab setting could be drastically different than field conditions - in this particular case, the lab measurement is a mere third of real-time consumption during in situ operations.

The need for conducting field testing is especially important for off-grid appliance, since in many cases, consumer use cases and preferences are not well understood. Field testing factors in different use cases and user behaviors to deliver critical insights into durability and product performance. The user feedback and in situ energy consumption measurements from field testing can further enhance laboratory testing protocols.

\section{Cost-benefit and business model considerations}

In terms of pricing, Devergy offers an 18-month installment program for the repayments; with a cost of 150,000 Tanzanian Shillings (equivalent of about $\$ 44$ ) to repay the fridge, and about the same cost for the energy used to power the fridge, per month.

Devergy reports that while customers would prefer the cost of the refrigerator to be lower, it is still priced at a point where they are willing to pay and able to afford it. The true constraint in socializing the off-grid refrigerator lies in convincing the customer that it is a good business model.

One of Devergy's entrepreneurs has reported making, on a daily basis, a profit equivalent to around $\$ 30$ at worst and an average of $\$ 70$ overall. He sells between 300 and 400 bottles per day, with each bottle reportedly being stored in the refrigerator for an average of $4-5 \mathrm{~h}$. In 2 days, he is able to repay the monthly expenditure of the refrigerator, including the cost of both the installment and the energy consumption, and is able to save the rest of his earnings.

The fact that Devergy is collecting sales data in tandem with technical monitoring helps draw broader conclusions around both Devergy's and the entrepreneur's respective business models. For the former, as $10 \%$ of the entrepreneur's revenues are identified as the sale of large bottles of water, it might make sense to offer the entrepreneur a solar water purifier as an additional appliance to support and grow his business. For the latter, as beer and soda bottles constitute about a quarter each of the overall revenue generated, this type of data can help leverage other sector partners to help finance the entrepreneur's refrigerator and increase their rural customer access. For example, Coca Cola has already entered such a partnership in the past with One Degree Solar in Kenya (Staff, 2013).

\section{Discussion of broader relevance}

The Devergy case study underlines the importance of differentiating between performance testing of off-grid products in the lab and in the field, for a more complete picture of efficiency gains as well as energy consumption and related considerations. 
It is worth noting that the issue of motivating customers to send consistent and high-quality data also has a significant potential to impact a field study like this one, especially at larger scales. While anecdotal data such as presented here and corroborated by the entrepreneurs' ledgers is relatively straightforward to crosscheck and confirm, with more units sold and out in the field, it becomes exponentially harder to keep track of user experiences and verify shared data points.

The use of mobile phones for such purposes reduces attrition and makes it easier for customers to send their data; however, this does not eliminate bias or selective sharing. For monitoring and evaluation purposes, in-person visits and occasional spot checks are still the best methods for an accurate representation of use and performance.

\section{Discussion and implications for off-grid appliance market}

Televisions, fans, and refrigerators are among the nearto-market products that represent a significant opportunity for scaling off-grid energy access. However, due to their relatively high technical complexity and cost, they also present a substantial risk for off-grid consumers and young, capital-constrained companies. Laboratory and field test data are an invaluable input to the business decision-making process of selecting appropriate products, and provides a way to verify — or dispute - manufacturers' energy performance claims.

The data trends presented in the previous section showcase a great need for an open, comprehensive database to facilitate this decision-making on appliance selection. The Efficiency for Access Coalition's Off-Grid Appliance Data Platform is a first step to address this need by giving users access to the most up-to-date product information, and enable them to easily compare and evaluate products based on critical attributes such as energy efficiency, quality, pricing, innovative features, and market availability.

Unlike on-grid markets, the majority of appliances in the off-grid retail market are not marked with a clearly declared energy performance value, making it extremely difficult for consumers to make informed decisions by comparing products based on performance, or understand the trade-off between cost and performance. Learning from the off-grid lighting sector, a strong quality assurance framework centered on performance reporting and truth-in-advertising requirements for such off-grid appliances could help better organize the appliance market, mitigate risks for buyers and consumers, and facilitate a variety of market support activities.

Two examples highlighting the challenges that could be addressed by a quality assurance framework, and sending a positive signal to the market, are discussed below.

\section{Accuracy of claimed energy performance values}

An assessment was conducted to illustrate the degree of deviation between manufacturers' rated energy performance values and laboratory tested data for fans and TVs (as most refrigerator suppliers do not declare a similar figure, they were omitted from the analysis). The results show high discrepancies between rated and tested values (Fig. 10). As indicated in the previous case study about Devergy refrigerator field testing, lab testing is often not the entire picture, and it is important to also do field testing to verify accuracy of test results in real-life conditions.

This level of discrepancy underlines the difficulty in making purchasing decisions based only on supplier declarations, and may not effectively champion product energy efficiency. Where consumption is higher than expected, this may lead to problems with unexpected power shortages or battery drainage in off-grid markets. In the European and American on-grid markets, concerns have also been raised over appliances that use more energy than formally stated, with estimates from the European market proving that around $10 \%$ of potential energy savings from more efficient products are lost from non-compliance (MarketWatch, 2018).

However, an early issue in the off-grid market may be that over-declarations could actually be inhibiting the uptake of efficient products. Consistent reporting of data, and a better understanding and communication of how this may vary in real-life settings, is therefore a crucial component to scaling a better informed and organized off-grid appliance market. Taking off-grid lighting sector as an example, the truth-in-advertising requirements in the Lighting Global Quality Standards for Pico-PV and SHS kits specify that key performance metrics, such as light output and solar, need to be reported on consumerfacing materials and to be accurately stated. This approach can be adopted by the off-grid appliance market to enable better communications and comparison of product performance. ${ }^{30}$

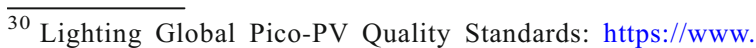
lightingglobal.org/wp-content/uploads/2017/09/Pico_MQS_v8_0.pdf.
} 


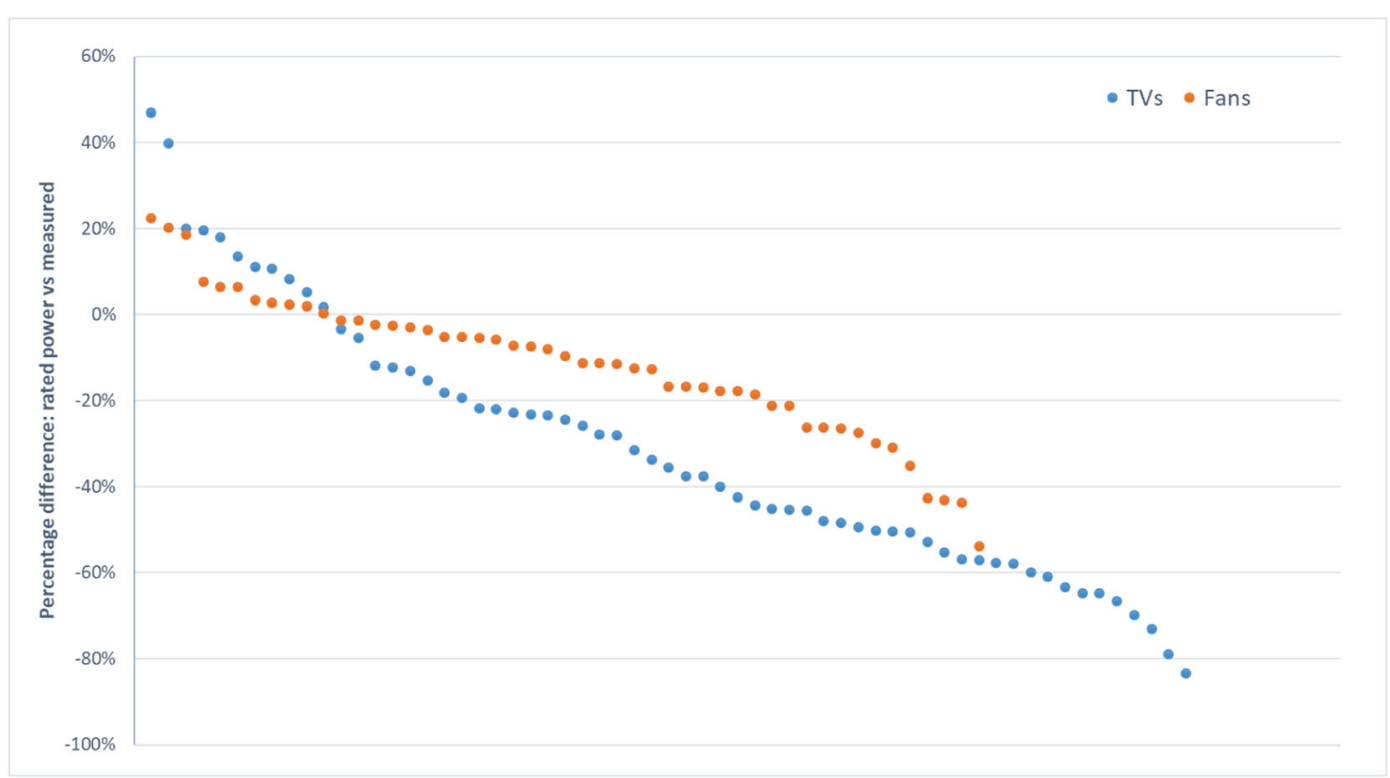

Fig. 10 Percentage difference between rated and measured power consumption values for TVs and fans (In this assessment, positive

Enhancing product durability and quality

Appliance durability and quality is extremely important for rural consumers - many of whom are the first-time users that are making a big investment in solar appliances. Product failures and bad user experiences can quickly erode consumers' confidence in such products. Therefore, methods for product testing under Global LEAP and for the Data Platform include quality inspections and durability measurements, such as over/undervoltage condition, drop tests, and ingress protection. Existing test data shows that all the TVs tested were able to meet the IP $2 \mathrm{x}^{31}$ ingress protection rating, but $22 \%$ of the products did not perform well in voltage fluctuation testing. Seventy-seven percent of fans tested failed the drop test, resulting in malfunction of motors, shattered motor casings, or damaged fan guards.

For the growing and sustained success of this market, a high level of confidence in the durability of products being offered is crucial; beyond market confidence, this may also affect such aspects as investor confidence, user safety, and e-waste considerations. Having appropriate quality assurance frameworks in place that do not only consider energy-efficiency, but also look at these

\footnotetext{
${ }^{31} \mathrm{IP} 2 \mathrm{X}$ indicates the protection against a solid objectives great than $12 \mathrm{~mm}$. For more information, please visit: http://temprecord. com/pdf/Temprecord\%20International\%20Ltd.\%20IP\%20Rating\%20 Information\%20Sheet.pdf
}

values indicate measured power was higher than rated figures.) Unpublished data sourced from CLASP

broader considerations more holistically and homogeneously, is a vital part of market development to inform stakeholders and champion quality products.

The analyses presented in this paper are a first attempt at gleaning existing and potential trends in efficiency, cost, and durability of off- and weak-grid appropriate TVs, fans, and refrigerators. Such analyses would be strengthened with more data made available. In particular, the authors recognize that sales data is a critical gap that remains to be addressed.

Funding This study was funded by The Good Energies Project (grant number 161915) and The Department for International Development's Low Energy Inclusive Appliances Program (grant number 300111-103).

\section{Compliance with ethical standards}

Conflict of interest The authors declare that they have no conflict of interest.

Open Access This article is distributed under the terms of the Creative Commons Attribution 4.0 International License (http:// creativecommons.org/licenses/by/4.0/), which permits unrestricted use, distribution, and reproduction in any medium, provided you give appropriate credit to the original author(s) and the source, provide a link to the Creative Commons license, and indicate if changes were made. 


\section{References}

Astor M. (2018). Hottest April day ever was probably Monday in Pakistan: a record $122.4^{\circ} \mathrm{F}$. In: The New York Times. https://www.nytimes.com/2018/05/04/world/asia/pakistanheat-record.html. Accessed June 2018.

Bertoldi, P., Lopez Lorente, J., \& Labanca, N. (2016). Energy consumption and energy efficiency trends in the EU-28 2000-2014. Publications Office of the European Union. https://doi.org/10.2788/581574. Accessed February 2019.

Climate Change and Health. (2018). Resource document. The World Health Organization. http://www.who.int/newsroom/fact-sheets/detail/climate-change-and-health. Accessed June 2018.

ComplianTV Product Database. ComplianTV . http://www. compliantv.eu/eu/product-database/. Accessed June 2018.

Derisking Renewable Energy Investment: Off-Grid Electrification. (2018). United Nations Development Programme, New York NY and ETH Zürich, Energy Politics Group, Zurich. https://www.researchgate. net/publication/329823440_Derisking_Renewable_Energy_ Investment_Off_Grid_Electrification. Accessed February 2019.

Euromonitor International. http://www.euromonitor.com/usa. Accessed June 2018.

European Commission. https://ec.europa. eu/energy/en/topics/energy-efficiency/energy-efficientproducts/fridges-and-freezers. Accessed June 2018.

The state of the global off-grid appliance market. (2016). Resource document. Global LEAP. https://s3.amazonaws.com/claspsiteattachments/The-State-of-the-Global-Off-GridAppliance-Market-Report.pdf. Accessed June 2018.

Global LEAP Awards 2017 buyer's guide for outstanding off-grid refrigerators. (2018a). Resource document. Global LEAP. https://static1.squarespace.com/static/56ba427f9f726695 ab77ec09/t/5a969f4124a694da85ab9282/1519820612724 /2017-Global-LEAP-Buyers-Guide-Refrigerators-January2018.pdf. Accessed June 2018.

Global LEAP off-grid refrigerator test method overview. (2018b). Resource document. Global LEAP. https://static1. squarespace.com/static/56ba427f9f726695ab77ec09/t/5ac2 a 177352 f5392d $2444 \mathrm{aba} / 1522704759316$ $/ \mathrm{G} 1$ o b a $1+\mathrm{LEAP}+\mathrm{Off}-$

Refrigerator+Test+Method+Overview+\%28Jan+18\%29. pdf. Accessed June 2018.

Global off-grid solar market report semi-annual sales and impact data. (2016). Resource document. GOGLA and Lighting Global. https://www.lightingglobal.org/wpcontent/uploads/2016/10/global_off-grid_solar_market report_jan-june_2016_public.pdf. Accessed February 2019.

Hammond, A. Kramer, W.J., Tran, J., Katz, R., Walker, C. (2007). The next 4 billion. Chapter 7, The Energy Market. World Resources Institute. http://pdf.wri.org/n4b_chapter7.pdf . Accessed February 2019.

Harrington L. (2009). A new global test procedure for household refrigerators. International Conference On Energy Efficiency in Domestic Appliances and Lighting. http://www. e n e r g y r a t i n g. gov.a u/s i t e s/n e w. energyrating/files/documents/2009-eedal-rf-testprocedure_0.pdf. Accessed February 2019.
Harrington L. (2015). Household refrigeration appliances: new star rating algorithm proposal for the IEC test method. Resource document. Energy Efficient Strategies for the Department of Industry, Innovation and Science. http://www.energyrating.gov.au/document/reporthousehold-refrigeration-appliances-new-star-ratingalgorithm-proposal-iec-test. Accessed June 2018.

Hirmer, S., \& Guthrie, P. (2017). The benefits of energy appliances in the off-grid energy sector based on seven off-grid initiatives in rural Uganda. Renewable and Sustainable Energy Reviews, 79, 924-934. ISSN 1364-0321 http://publications. eng.cam.ac.uk/908784/. Accessed February 2019.

Leo B, Kalow J, Moss T. (2018) What can we learn about energy access and demand from mobile-phone surveys? Nine findings from twelve African countries. Policy paper. https://www.cgdev.org/sites/default/files/what-can-we-learnabout-energy-access-and-demand-mobile-phone-surveys. pdf. Accessed February 2019.

Market Watch. http://www.market-watch.org.uk/about-us/. Accessed June 2018.

Off-Grid Appliance Market Survey. (2017). Resource document. Global LEAP. https://static1.squarespace.com/static/56ba427 f9f726695ab77ec09/t/5a29bec841920214496ca521 / $1512685258988 / 2017$ + Off Grid+Appliance+Survey+Summary.pdf. Accessed June 2018.

Off-Grid Appliance Market Survey. (2018). Resource document. Efficiency for Access Coalition. https://storage.googleapis. com/e4a-website-assets/Market-Survey-2018.pdf. Accessed February 2019.

Off-Grid Solar Market Trends Report 2018. (2018). Resource document. International Finance Corporation. https://www. gogla.org/sites/default/files/resource_docs/2018_mtr_full_ report low-res 2018.01.15 final.pdf. Accessed June 2018.

Park, W., \& Phadke, A. (2017). Adoption of energy-efficient televisions for expanded off-grid electricity service. In Development Engineering/volume 2, 2017, pages (pp. 107113). https://doi.org/10.1016/j.deveng.2017.07.002 h t t p s : / / w w w . s c i e n c e d i r e c t. com/science/article/pii/S2352728516300057. Accessed February 2019.

Park, W., Gopal, A., \& Phadke, A. (2017). Energy savings opportunities in the global digital television transition. Energy Efficiency https://doi.org/10.1007/s12053-016-9500-5. Accessed February 2019.

Phadke, A., Jacobson, Arne, Park, W.Y., Lee, G.R., Alstone, P., and Khare, A.W . (2015). Powering a home with just 25 watts of solar PV. Super-efficient appliances can enable expanded off-grid energy service using small solar power systems. United States. doi:10.2172/1229861. https://www.osti. gov/servlets/purl/1229861. Accessed February 2019.

Sathaye, N., Phadke, A., Shah, N., \& Letschert, V. (2012). Potential global benefits of improved ceiling fan energy efficiency. California: LBNL-5980E. Lawrence Berkeley National Laboratory.

Seeking end to loss and waste of food along production chain. (2018). The Food and Agricultural Organization of the United Nations. http://www.fao.org/in-action/seeking-endto-loss-and-waste-of-food-along-production-chain/en/. Accessed June 2018. 
Shah, N., Park, W.Y., Bojda, N., McNeil, M., Waide, P. (2014). Superefficient refrigerators: opportunities and challenges for efficiency improvement globally. 2014 ACEEE summer study on energy efficiency in buildings. ACEEE. Accessed February 2019.

Shah, N., Sathaye, N., Phadke, A. et al. (2015). Energy efficiency. 8: 37. https://doi.org/https://doi.org/10.1007/s12053-0149274-6. Accessed February 2019.

Staff J. (2013). Bringing solar power to off-the-grid retailers in Kenya. In The Coca-Cola Company https://www.cocacolacompany.com/stories/let-there-be-light-bringing-solarpower-to-rural-retailers-in-kenya. Accessed June 2018.

Topten Switzerland https://www.topten.ch/. Accessed June 2018.

Topten UK http://www.toptenuk.org/private. Accessed June 2018.
Tulapurkar, C., Subramaniam, P.R., Thagamani, G., \& Thiyagarajan, R. (2010). Phase change materials for domestic refrigerators to improve food quality and prolong compressor off time. International Refrigeration and Air Conditioning Conference. Paper 1044. https://docs.lib. purdue.edu/cgi/viewcontent.cgi?referer=https://www. google.com $/ \&$ httpsredir $=1 \&$ article $=2043 \&$ context=iracc. Accessed June 2018.

Urmee, T., Harries, D., Holtorf, H.G. (2016). Photovoltaics for rural electrification in developing countries. doi: https://doi. org/10.1007/978-3-319-03789https://www.springer. com/us/book/9783319037882. Accessed February 2019.

Publisher's note Springer Nature remains neutral with regard to jurisdictional claims in published maps and institutional affiliations. 